PROCEEDINGS OF THE WORLD BANK ANNUAL CONFERENCE

ON DEVELOPMENTECONOMICS 1990

\title{
FILE COPY Regional Sustainable Development and Natural Resource Use
}

\author{
Peter Nijkamp, C. J. M. van den Bergh, and Frits J. Soeteman
}

\begin{abstract}
The concept of sustainable development has been discussed intensively at a global level in the past few years. This paper investigates sustainable development in a practical planning context by introducing and outlining the notion of regional sustainable development (RSD)-a translation and operationalization of sustainable development on a regional scale. Implicit in RSD is that it should always be compatible with global sustainability and that $R S D$ of all regions of a spatial system implies sustainable development for the system as a whole. From a planning viewpoint, an identification of critical success factors (CSFS) is of crucial importance for RSD. A CSF is a necessary condition for balanced regional development that can be guided by policy intervention. In most cases, the notion of sustainable resource use (SRU) appears to provide a practical framework for identifying a CSF, because renewable stocks of natural resources are a key factor for RSD in most countries. CSFs may usually be found by investigating the regional supply of natural resources and using their features (exhaustible, renewable, accessible, multifunctional, and so on) to identify measurable indicators for RSD. The paper discusses and critically evaluates RSD models with regard to their design, specification, and use. In addition, it presents three case studies that may help clarify the notions of RSD, CSFs, and SRU and demonstrate their operational character in different regions: the Peel area in the Netherlands, the Sporades Islands in Greece, and rural land in Botswana. The paper concludes with retrospective review and a prospective exploration of important research questions.
\end{abstract}

\section{RECENT ENVIRONMENTAL IsSUES}

The 1970s marked the beginning of the broad awareness of actual and potential conflicts between economic progress in production, consumption, and technology and the environment. Since then, the environment has become the subject of intensive research in both developed and developing nations. In various countries, "standard" types of environmental pollution-notably air pollution, water pollution, solid waste, and noise-have been tackled fairly successfully, at least on a local scale. Most abatement policies have been oriented toward envi-

Peter Nijkamp is professor of economics in the Faculty of Economic Sciences and Econometrics at the Free University of Amsterdam. Jeroen C. J. M. van den Bergh and Frits J. Soeteman are also with the Faculty of Economic Sciences and Econometrics at the Free University of Amsterdam.

(C) 1991 The International Bank for Reconstruction and Development / THE WORLD BANK. 
ronmental issues of a tangible-often local or regional-nature. Moreover, a large number of regulations have been introduced in the field of industrial pollution, sewage treatment, protection of landscapes, conservation of monuments, and so on.

As a reading of the literature makes evident, the policy and research focus on urgent environmental issues has been marked by fluctuating patterns over the past few decades. The first wave of massive environmental concern, in the 1970 s, mainly called attention to negative externalities and their social costs in the form of environmental pollution, and to resource depletion (notably in the fields of energy resources, minerals, and fisheries) connected with the industrial structure of our economies. This interest was further intensified by the heightened public awareness of the deleterious consequences of various specific chemical processes, technologies, and forms of household consumption (for example, smoking and automobile use).

In the past decade, however, a shift has taken place from partial environmental analysis to a focus on, first, global-regional interactions and, second, economic-ecological interactions of environmental problems. There is an increasing recognition that a more coherent approach is needed in dealing with environmental issues, including land use, urban development, common property resources, spatial inequality, and intergenerational equity.

Global-level environmental interactions have been marked by two features. One is the globalization of environmental impacts. The other is the regionalization of an often hardly visible but quite substantial decline in the quality of global environmental resources.

The global effects of environmental decay-reflected among other things in alarming phenomena such as ozonization, desertification, and acid rain-came in most cases as scientific surprises and were hardly addressed in actual policymaking until recently. But, especially since the publication of the report of the Brundtland Commission (WCED [World Commission on Environment and Development] 1987), we have witnessed a significant increase in interest in global environmental problems.

In addition to global issues, a large number of small-scale and marginal changes at the local or regional level have clear global dimensions. A wide variety of incremental pollution phenomena (for example, persistent micropollutants), seemingly hardly important by themselves, have severe accumulative and synergetic environmental impacts. All such impacts call for more coherent local environmental planning. In this respect, local land use is becoming one focal point of concern for policymakers and researchers.

The spatial issue can thus be examined from the viewpoint of local trends causing global effects and global trends leading to local effects. An illustration of the first type of problem is poor natural resource management in some countries, which threatens both the physical basis of these countries and also destroys the vulnerable ecosystem of the planet to an unprecedented extent. Other illustrations of local-to-global influence are cases of overgrazing and deforestation 
that may lead to wider soil erosion, sedimentation, flooding, and salinization. The second type of problem concerns the local-scale environmental effects that emerge from global trends. Acid rain, erosion, desertification, destruction of the ozone layer, eutrophication, ocean pollution, and resource extraction are taking place on a worldwide scale, but their effects can clearly be observed at a local or regional scale. Thus, the global-regional interdependence of environmental problems confronts us not only with quantitative changes but also with qualitative (or structural) long-term changes at all places on earth (see Bartelmus 1986). This calls for a new view of spatial economic-environmental problems and policy issues.

The economic-ecological interactions arise in general because concerted socioeconomic development requires a compromise between material growth and environmental constraints, including environmental quality and vital natural resources. Although in different countries the conditions under which a balanced development may come about will show much variation, the conflicting nature of the above objectives is evident in all countries. Especially in the short run, the conflict between material growth and environmental quality may be rather severe; in the long run, a mitigating effect may emerge, because continued economic growth needs a sound resource base, and structural protection and upgrading of environmental quality in turn presuppose economic growth (see also Nijkamp and Soeteman 1989 and Shefer 1974). Such a coevolutionary development (Norgaard 1984), in both the developed and the developing world, takes for granted that economy and ecology ultimately do not conflict with one another. But such a coevolution-even one that is also based on equitable development options for present and future generations-does not necessarily require mutual positive spillover effects between the economy and the ecology. It is this latter idea that is more recently echoed in the notion of ecologically sustainable economic development.

Given the growing prominence of environmental problems, it is no surprise that sustainable development has become a key catchphrase in economic planning and resource management. However, the interpretation of this concept is still ambiguous, and definitions of it are abundant-ranging from continued economic growth to steady state economies where economic growth mainly serves to compensate for environmental depreciation (a more extensive overview of definitional problems can be found in Archibugi and Nijkamp 1989; van den Bergh and Soeteman 1990; and Pezzey 1989). As a result, even though the idea of sustainable development has dominated most recent discussions on development and environment, the actual effects of this idea are not yet clearly visible in terms of a drastic reorientation or new departures for socioeconomic development policy (see also Collard, Pearce, and Ulph 1989). Clearly, balanced strategic planning based on merging the principles of economics and ecology appears to be difficult. Only a few examples so far convincingly demonstrate that a concerted reconciliation of seemingly conflicting options-at least in the long run-is not impossible. 
According to the Brundtland Report (WCED 1987), the idea of sustainable development reaches far beyond environmental protection, as it means a process of change in which exploitation of resources, direction of investments, orientation of technological development, and institutional changes are made consistent with future as well as present needs. Consequently, sustainable development is not a fixed state of harmony but rather a balanced and adaptive process of change. This would then be characterized by a dynamic Pareto-optimal trajectory in which progress in one system-that is, either the economic or the ecological-would not be to the detriment of the other system. Sustainability takes for granted a balance between economic development-all quantitative and qualitative changes in the economy that offer positive contributions to welfare-and ecological sustainability-all quantitative and qualitative environmental strategies that serve to improve the quality of an ecosystem and hence also have a positive impact on welfare.

It is noteworthy that the concept of welfare has to be understood here in a broad sense as the individual or collective utility derived from the availability or use of scarce commodities, including environmental goods, whether such utility attributes can be measured in monetary terms or not (see Nijkamp and Soeteman 1988). Consequently, toxic materials, ionizing radiation, the beauty of the landscape, well-preserved monuments, traffic safety, wholesome food, and availability of shelter all may be regarded in principle as arguments in a welfare function.

For example, in the framework of agricultural land use, the welfare gains from agriculture should be measured by income or production generated in the agricultural sector, but they should also incorporate negative effects on the landscape, species diversity, or ecostability (see also section VI). Clearly, various changes in land use patterns may be caused by factors outside the agricultural system itself, such as the climate.

The fact that both conventional economic factors and environmental goods may contribute to welfare, and must also be traded off against each other, does not of course imply that in an extreme case one of the two systems might be completely depleted. Both economic and environmental systems need a certain minimum threshold value to survive. Ciriacy-Wantrup (1952) advocated the use of a minimum bequest value in strategic environmental policies, in particular calling for the establishment of safe minimum standards for conservation by avoiding overexploitation of critical zones of the environment by limiting human activities that make it uneconomical to halt or reverse depletion. Thus, the idea of sustainable development requires a careful consideration of sustainable threshold levels for both economic and environmental systems.

It is clear from the above remarks that sustainable development issues are manifesting themselves in various forms. An extremely important form is land use and uses of land-related resources. For example, deforestation in Brazil may be necessary for agriculture or energy supply in a regional economy, but it is extremely detrimental to global ecological stability. Housing construction in 
densely populated areas may be necessary from the viewpoint of a growing population and a decline in family size, but at the same time it may impair the visual beauty of an ecologically vulnerable area. Thus, to a large extent, land use may be regarded as a focal point of sustainable development policies in a spatial setting. This leads to the necessity to specify more precisely the interactions between different resource and land use options in a given area and the spillover effects from, and to, other areas. Such a more local and regional orientation is mandated not only by the character of the economic and environmental interactions but also by the spatial orientation of policies concerned with land use.

Our study focuses attention on the spatial dimensions of ecologically sustainable economic development in the context of regional resource use affecting land use. In other words, we discuss the issue of regional sustainable development in relation to land use. Our paper clarifies the intricate relationships between ecology and the economy in land use by bringing together in a structured way relevant recent literature and by elaborating, clarifying, and operationalizing the notion of regional sustainability with particular emphasis on the identification of critical success factors for RSD.

\section{Land Use, Regional Sustainable Development, and Sustainable Resource Use}

Conflicts between economic progress and environmental sustainability are not exclusively a phenomenon of recent decades. Even in ancient times, Plato was concerned about landscape changes in Attica, as witnessed by his complaint in the Critias that recent developments had turned the environment into "bones of a wasted body . . . richer and softer parts of the soil having fallen away, and the mere skeleton being left" (cited in Clark 1986, p. 8). Changes in land and resource use associated with agriculture, industry, or urban development in many European countries also have affected landscapes (and related environmental conditions) in all periods between nomadic cultures and modern industrialization. Until World War II, the land use implications of a mixed agricultural and industrial society were relatively modest. Postwar land use, however, has been influenced not only by industrial activity in many countries but also by urbanization and recreation. Consequently, land use is rapidly becoming a focal point of environmental-economic research.

The broad recognition of resource and land use as an issue for scientific research is quite new in economics. Apart from the Physiocrats, who regarded the productive capacity of the natural environment (mainly land) as the major source of welfare, economic thinkers until recently have rarely paid due attention to land as an important production factor. For example, in classical economics, capital and labor, not land, were regarded as the main welfare generators. It is interesting to note, however, that the classical economists were aware of the possibility that an economy might stagnate as a result of lack of naturalmainly agricultural-resources. 
Largely as a result of neoclassical thinking in the post-World War II period, nature was not considered the source of welfare but merely the supplier of raw material subsequently used by labor and capital. Clearly, land did not become irrelevant, but in the words of Randall and Castle (1985), "there seemed no reason to accord land any special treatment that would suggest its role is quite distinct from that of the other factors. Land could safely be subsumed under the broader aggregate of capital" (p. 573).

From the viewpoint of land use, there is now a clear need to pay more explicit attention to the spatial scale of environmental phenomena. A main question is how to avoid a "tragedy of the commons" in view of the long-term threats exerted by seemingly inevitable and persistent changes in land use at both a local and a global scale. In principle, in a giobal system, all processes are endogenously determined, whereas in a mesosystem (for example, a single region), a considerable part of the relevant economic and environmental processes is exogenously determined. Such external influences do not have a uniform effect on all regions of a global system. For example, global warming of the atmosphere may lead to a rise in total organic production in the world as a whole, but no doubt will lead to different socioeconomic and ecological impacts in various regions of the world. Furthermore, regions of a global system form an open set of mutually interacting areas, so that certain changes in one area have consequences for other areas. For example, Arntzen (1989) has shown that spatial mobility of human activities in an open system of regions-as a result of periods of drought-may induce resource pressure in other areas in a developing country. Thus, at a regional level of analysis, there is much scope for various spatial tradeoffs: interregional, regional-global, and intertemporal. This leads us to the notion of regional sustainable development as a particular type of sustainable development in an open spatial system (see also Kairiukstis 1989).

In a spatial setting, RSD refers to both the potential offered by the environment as a resource base for economic growth and to the constraints imposed by the environment on an unlimited growth potential, while taking into consideration the mitigating or reinforcing effects of environmental dangers caused by an open spatial system.

If a given region's RSD is independent of the rest of the world, then it is selfsufficient; it may be regarded as a closed system. More interesting and relevant, however, are open regions. In an open multiregional system, the final result for RSD depends, among other things, on the type and volume of goods and services the region offers to the rest of the world. Interregional trade, which in the standard literature is supposed to be determined by comparative cost advantages and scale economies, may have a distorting impact on sustainability in an open spatial system, of course, unless all negative environmental externalities are included as imputed social costs in spatial trade flows. Thus internalization of external costs is a prerequisite for RSD.

Aside from assessing regional variation and regional interaction, there is another reason for focusing attention on a regional scale-that is, the fact that a 
regional system is more amenable to policy management, examination, and control than a global system. In this context, planning regions may allow for the attainment of certain planning objectives in the most efficient way (see Paelinck and Nijkamp 1976).

A region is a geographical area that meaningfully may be regarded as a coherent entity from the viewpoint of description, analysis, administration, planning, or policy. Various types of regions are distinguished in the literature-for example, homogeneous or functional regions. Functional environmental regions are often based on intensive interactions within particular regions between environmental resources such as groundwater, river, and meteorological systems. Homogeneous environmental regions are usually based on the existence of common resources in the area concerned. Another typology distinguishes natural (ecological or environmental) regions, economic regions, and administrative (or political) regions (Paelinck and Nijkamp 1976).

Regional development is often critically dependent on the regional supply of resources. Many types of regional economic dependence on the resource base can be distinguished (see van den Bergh and Nijkamp 1990). Some examples follow:

- A regional economic system may be directly dependent on the resources in the region. Usually in such cases the dependence is on resources that may serve as essential and cheap productive inputs to economic activities-for example, energy resources. Concomitantly, the environmental capacity as a sink for waste materials and pollution can restrict economic activity.

- Some regions may be dependent on export of resources as a main source of income-for example, energy-exporting boom towns in the province of Alberta, Canada.

- A regional resource sector may have many effects on other activities in a region, among other things as a result of an increased demand for public services, utilities, and infrastructure; demand for labor, capital, and space; and spinoffs to other private sectors. Thus, the development of a resource sector may generate shifts in sector allocation, income levels and distribution, and exchange rates.

From a welfare viewpoint, it makes sense to define RSD as development that ensures that the regional population can attain an acceptable level of welfareboth at present and in the future-and that this regional development is compatible with ecological circumstances in the long run while it also tries to accomplish a globally sustainable development. Clearly, specification of minimum bequest values, implementation of shadow projects, or allowance for limited but given substitutability between productive and environmental capital are special cases of RSD. Also, knowledge transfer or technology transfer for preventive environmental policies may be relevant in this framework. Consequently, RSD has to fulfill two goals (see van den Bergh and Nijkamp 1990). First, it should ensure for the regional population an acceptable level of welfare that can be 
sustained in the future. Second, it should not conflict with sustainable development at a supraregional level.

The latter goal implies that RSD for a single region as a spatial decisionmaking unit should be compatible with global sustainable development. Consequently, if all regions of a global system are marked by RSD, the development of the global system will be sustainable as well. Clearly, the RSD paths of specific regions may have different characteristics because of specific regional circumstances, for example, availability and use of natural resources and socioeconomic capital, environmental vulnerability and resilience, and socioeconomic distribution of income and employment. Thus, it is not easy to typify RSD in general terms.

Given the existence of trade, transport, dispersion of species, or other socioeconomic and ecological linkages between regions, it may be possible to attain sustainable development at a global level without having RSD at the regional level. In extreme cases it might even be possible that global sustainable development demands that regions "sacrifice" some degree of their own development, welfare, or environmental sustainability. Such detrimental effects may be acceptable from a supraregional (or global human need) perspective. This situation of a retreat to "weak sustainability" may happen, for example, when certain regions are used for specific environmental or economic purposes (such as conservation, concentration of industrial activity, or dumping of waste). According to the Brundtland Report (WCED 1987, p. 45), it is not even realistic to suppose that every ecosystem (which may encompass more than one region) can be preserved and kept intact everywhere. In these cases we have to look for regional implications of sustainable development, which may call for solutions to the difficult problem of regional compensation for welfare losses.

Compensatory measures can be used for both spatial and time phenomena. The idea of such compensation is appealing because it allows alternative policy choices over space and time. However, in various practical situations, many questions still must be answered to make this option really operational. One question is how compensation is allocated (for example, what are the environmental and socioeconomic consequences of the compensating project?). Other issues involving regional compensation may relate to the possible time lags between destruction of environmental amenities and their reconstruction or to the costs to be borne by various groups. Recently, various interesting proposals have been made in this context. One is to replant forests in Central America as a compensation for the carbon dioxide produced by a new power station in New England. Of course, the idea of compensation is easier to apply to large individual projects with a single decisionmaker. For numerous small daily decisions by individual persons (such as painting a house, driving a car, or smoking a cigarette), direct compensating measures are hard to carry out because of the socalled large number case (see Baumol and Oates 1988).

To provide a more concrete and operational approach to RSD, we may focus attention on a more limited issue: sustainable resource use (SRU). This applies 
mainly to renewable stocks of natural resources (for example, forests) and reflects the idea that the use of goods and services provided by such a resource base can be regulated to maintain an optimal stock level. We define a resource base here as the complex of resources and their regenerative support systemsresources that are critically important for regional welfare. Sustainable use of a region's stock of resources may be regarded as an important, though not sufficient or even necessary, condition for RSD. Such a conservation strategy is a kind of risk-avoiding strategy. If a stock of renewable resources is used wisely, it may generate a flow of materials, services, or both for an unlimited period. If this flow is sufficient for generating an acceptable welfare level for the regional population ("sustainable welfare"), it is clear that it is of advantage to aim at conservation of the resource. Thus, resource management is a critical variable, because overuse or extinction of a resource is in most cases irreversible. Moreover, SRU guarantees regional income at least for a considerable time. RSD may then provide an appropriate bridge between SRU and sustainable development.

An important concept in this framework is the carrying capacity of a region, which refers to the existence of ecological upper limits to a further increase in the economic system, often reflected in a logistic growth path of a region. When applied to human population in a region, carrying capacity may indicate the number of people that a region can support. In other cases it may be used as an indication of the number of tourists the region can accommodate. Three major aspects play a role in the determination of carrying capacity: biophysical elements, behavioral elements, and economic amenities. The first aspect includes spatial densities, stress factors related to ecosystems, sensitivity of animal and vegetation species, soil, climate, and groundwater and surface water characteristics. In the second category fall spatial interaction, congestion, and crowding, which can be related to preferences of the population, tourists, or both. The third category includes the supply of goods and services, housing facilities, and employment. Carrying capacity is essentially a dynamic concept; it presupposes a proper and flexible management of natural environments over time, so that, for example, some biophysical aspects may become less constraining. Especially, economic amenities can be influenced to improve the carrying capacity.

Carrying capacity can be used to determine the boundaries of a feasible RSD or SRU. Some of the other features of a resource base that are useful in this context are exhaustibility, potential depletability, multifunctionality, stability, private versus public ownership, and whether the resource base is a closed or open system. The question of which variables are of critical importance for the attainment of RSD is discussed in the next section.

\section{CRitical Success Factors for RSD}

RSD and SRU are not just theoretical concepts; they also serve as a practical guideline for regional development policy. As suggested above, RSD serves to 
find a balance between the following objectives (compare Siebert 1987 and World Bank 1987):

- Economic progress and/or potential of the area concerned

- Ecological values and/or constraints of the area concerned

- The economic and environmental interest of parties not directly involved (other regions; different generations).

These three objectives are certainly mutually conflicting, at least in the short run, because a maximization of any one objective will affect the two remaining ones. In the long run, however, these three objectives are less conflicting; instead of substitution a situation of mutual complementarity (or coevolution) may emerge. A critical success factor then may be interpreted as a particular crucial variable whose availability or presence is able to enhance-in a qualitative or quantitative sense-the performance of at least one objective without reducing the performance of the remaining ones (a Pareto-optimal condition).

Critical success factors for RSD can also be seen as the necessary conditions that act as crucial variables for the attainment of a balanced development in terms of RSD or SRU in a region. Examples of such critical success factors are the availability of water in arid or semiarid areas in view of the needs of agriculture, industry, and households; the existence of accepted institutional rules for the management of a common resource pool (for example, in the fishery sector); and the presence of limits to growth caused by the carrying capacity of a region. Clearly, a critical success factor presupposes that it can-directly or indirectlybe influenced by public policy measures oriented toward the attainment of RSD.

To identify critical success factors in RSD, a stepwise approach may be followed. In view of the great many different types of potential uses of a resource base, as well as human preferences for and the characteristics of the resource base, one should identify which factors are most relevant for a specific regional development plan.

A first and obvious step in this analysis of RSD is the delineation and characterization of the region. Given the multidimensional nature of RSD, a wide variety of different types of regions can be distinguished-for example, developed regions, densely populated areas, urban regions, industrial areas, environmentally protected areas, regions lagging in many aspects, islands, and recreational areas. It is impossible to typify a set of regions a priori in an unambiguous manner according to such fairly general criteria for RSD. Only when regional characteristics are specified in more detail, and regional development objectives are formulated, is it possible to typify RSD. For this reason, research on RSD should be devoted partly to case studies of various types of regions, an approach adopted below.

A meaningful regional classification from the viewpoint of RSD may be based on the following characteristics of the regions under consideration: socioeconomic circumstances, economic development phase, level of pollution or congestion, natural resource base, and regeneration and depletion rates of resources. 
A second step in the analysis of critical success factors in RSD is a stocktaking of the characteristics of the internal structure of a region, its interactions with other regions, and other relevant global impacts. Using this information, one may arrive at a clearer view of the potentials for and constraints on the region's future development. One may also extrapolate from past and present situations to determine feasible future states or scenarios of the regional system concerned.

A third step in identifying critical success factors involves assessing both probable and uncertain developments and those that deviate from the extrapolated path. Probable developments include expected policy actions, changing preferences because of a scarcity of amenities, expected technological developments, investment programs, conservation strategies, or social welfare programs. Uncertain and more drastic developments may involve the disappearance of old economic sectors, the emergence of new sectors, drastic changes in public investments, and changes in institutional arrangements. The assessment of future developments relevant to RSD also should entail extraregional developments, especially with respect to resource availability, demand for exports, world market prices, international competition, and external pollution emissions.

A fourth step in critical success factor analysis is identifying and evaluating different development paths for the regional system concerned. As a first step, a set of performance indicators and an evaluation method must be decided upon. Two types of indicators are important in the evaluation of RSD. The first type indicates the desirability of a state of the system at a point in time. The static welfare indicators may include income distribution, regional income per capita, sectoral diversity, unemployment, public services, infrastructure, land use, level of congestion, amount of vegetation, species diversity, and water quality. The second set of indicators that must be developed for dynamic evaluation encompasses information about the potentials and constraints for future development of a regional system.

In evaluating the time paths of indicators and in case of multiple indicators, use of multicriteria techniques for the evaluation of alternative development options with respect to RSD seems logical. But an explicit policy evaluation of specific indicator outcomes is not easy, and important issues such as stability and fluctuations cannot always be included directly. Then, the use of constraints for demarcating acceptable development paths seems more useful. This also comports with the fact that RSD does not give rise to simple judgment criteria and it certainly will not result from optimizing a single criterion.

\section{Institutional Policy Aspects of RSD}

An integrated regional policy may be centrally organized, delegated to lower levels (regional, local) or organized from the viewpoint of functional specialization. This assignment problem of competencies and operational tasks is a focus of this section, which seeks to make a first step in designing a framework for integrated regional policy organization oriented toward the achievement of RSD or SRU. 
Clearly, in the framework of RSD an integrated economic and environmental approach to policymaking is a necessity. However, its implementation will face a variety of difficulties. One of these difficulties is related to the institutional structure and competence of regional planning (see Zimmermann 1982). In this context, the institutional structure refers to the whole system of rules and regulations by which competencies, tasks, and responsibilities are divided among actors.

Present planning structures have evolved over a long time. In general, new governmental tasks and responsibilities emerge as a result of the perceived imperfect working of the market economy. Consequently, rooted in their own specific historical backgrounds, separate planning cultures have evolved-for example, housing programs arose as a result of bad hygienic circumstances at the end of the last century; employment planning as a result of the depression in the period before World War II. Physical planning became popular in the $1920 \mathrm{~s}$ as a result of an unbalanced development between industrialization, housing, and transport. Environmental and social planning are the most recent developments in this respect.

A general characteristic of many of these planning efforts is that in early phases of planning the emphasis was mainly on prohibitions and regulations, whereas in later phases more emphasis has been laid on conditions for development. This is certainly true for environmental planning. It started with measures coping with the negative environmental externalities of production and consumption processes. Nowadays there is a tendency toward more source-oriented policies.

It will be clear that a development policy in which environmental policy will be a key factor for welfare development is impossible without a simultaneous design of coordination channels between the various functional areas of policy concern. Many coordination problems are the result of the above-mentioned historical roots of segmented planning. The coordination problems may also be the result of a different educational background of specialists, separate planning languages, separate planning horizons, use of different data bases, lack of integrated formal and evaluation models, and use of different performance indicators.

Another issue in the context of coordinated and integrated planning is hierarchical structuring. A hierarchical planning design may be seen either from the viewpoint of responsibilities and tasks delegated to various levels or from the viewpoint of a hierarchical division of goals.

An advocate of a more economic approach to institutional assignment problems is Zimmermann (1982), who formulated some guidelines with respect to the choice of the level at which an environmental policy should be carried out:

- Degree of uniformity or diversity of regional preferences with regard to certain environmental and socioeconomic goods and services (especially with regard to equity aspects) 
- Degree of economies of scale regarding the supply and provision of environmental goods (especially with regard to efficiency aspects)

- Extent of spillover effects (both equity and efficiency aspects are relevant here).

Economics seems to provide at least some meaningful guidelines for a demarcation of planning responsibilities, although ecological considerations also should be taken into account. The National Physical Planning Agency in the Netherlands defines environmental policy as "the stimulation of certain spatial and ecological conditions in such a way that the real aspirations of individuals and groups in society can be realized to a full extent" and "the diversity, coherence and sustainability of the physical environment can be guaranteed as much as possible."

Administrative and legal boundaries seldom coincide with those of the environmental problem region concerned. This has resulted from the fact that environmental problems are often being carried out on the basis of assigned responsibilities without special emphasis on the spatial dimensions of the environmental problem. To carry out a proper policy-oriented toward RSD-the assignment should also be based on spatial ecological characteristics of the problem (Klijn 1988).

To clarify the latter observation, table 1 illustrates some environmental problems and the spatial range of their impact. For example, climatic change is a process that takes hold in the atmosphere and works through the whole ecosystem. Therefore, an efficient policy to influence this process necessitates a global planning approach. It is thus plausible that from an ecological point of view that an institutional assignment of responsibility should be derived from the spatial impact of the environmental problem (see Clark and Munn 1986).

A proper environmental policy also should take account of interdependencies

Table 1. Environmental Problems and the Spatial Range of Their Impact

\begin{tabular}{|c|c|c|c|c|c|c|c|c|}
\hline \multirow[b]{2}{*}{$\begin{array}{l}\text { Spatial range of } \\
\text { impact }\end{array}$} & \multicolumn{8}{|c|}{ Environmental problem } \\
\hline & $\begin{array}{l}\text { Climatic } \\
\text { change }\end{array}$ & $\begin{array}{l}\text { Acidifi- } \\
\text { cation }\end{array}$ & Pollution & $\begin{array}{l}\text { Nutrifi- } \\
\text { cation }\end{array}$ & $\begin{array}{l}\text { Aridifi- } \\
\text { cation }\end{array}$ & $\begin{array}{c}\text { Destruc- } \\
\text { tion }\end{array}$ & $\begin{array}{l}\text { Disper- } \\
\text { sion }\end{array}$ & $\begin{array}{l}\text { Distur- } \\
\text { bance }\end{array}$ \\
\hline $\begin{array}{l}\text { Atmosphere } \\
\text { Geomorphological }\end{array}$ & o & o & o & & & & & \\
\hline structure & & & o & & & o & & \\
\hline Relief & & & & & & o & & \\
\hline Groundwater & & & o & o & o & & & \\
\hline Surface water & & & $\mathbf{o}$ & 0 & o & o & & \\
\hline Soil & & o & $\mathbf{o}$ & o & & o & & \\
\hline Vegetation & & & & & & o & 0 & \\
\hline Animal life & $\downarrow$ & $\downarrow$ & $\downarrow$ & $\downarrow$ & $\downarrow$ & $o$ & $\downarrow$ & o \\
\hline
\end{tabular}

$o:$ intervention point.

$\downarrow$ : impact of environmental problem on ecosystem.

Source: Klijn (1988). 
between regions. According to Odum (1971), the main goal of environmental policymakers should be to minimize the impact of human activities on the environment from the perspective of ecosystems.

Clearly, because environmental and socioeconomic variables influence each other, a coherent policy is necessary to find a balance between these variables. But a coherent policy does not mean that it should automatically be implemented at a centralized level. Decentralizing national policy, however, raises some difficulties. For example, regional or local agencies may strive for maximization of welfare of their own region, thereby neglecting the interregional effects of some of their activities or measures (spillover problems; see Siebert 1985). In addition, environmental media may differ as far as their spatial coverage is concerned. This implies that the planning regions will overlap, which in turn will create coordination problems (Ewringmann and Hansmeyer 1980).

Decentralization of environmental policy may be justified because regional authorities are in a better position to identify regional preferences and to implement regional targets, and they will normally be better informed than national authorities regarding the implementation or successes of environmental policy instruments (Siebert 1985). Horizontal coordination between economic and environmental policy also may lead to greater efficiency.

In this context it might be useful to distinguish between institutional policy aspects and executive policy aspects. Institutional policy aspects are related to the distribution of responsibilities over various policy levels (constitutional power). Executive policy aspects are related to decisions taken during the policy period to ensure that the policy goals are achieved (executive power).

It is evident from the previous remarks that the existence of a proper institutional assignment is a critical success factor for RSD, especially in view of the differences in spatial coverage of economic and environmental policies.

\section{Models for Sustainable Development}

Sustainable development has induced many scientific discussions on the intricate relationships between economy and ecology, but by no means has it led to a proper specification analysis of suitable models. The issue of RSD-and also the identification of critical success factors-inevitably evokes the question of appropriate model design and structure. An important problem is which specific type of model is relevant for gaining insight into RSD conditions or for tracing RSD paths. This question may be dealt with by focusing on model structure and specification aspects on the one hand and model use and evaluation aspects on the other (see van den Bergh and others 1990).

The most significant features of models for sustainable development that distinguish them from other models used for environmental problems are the following:

- A module that describes the dynamics of resource bases and ecosystems; the 
indirect effects and consequences of specific economic developments for natural environments can then be traced.

- Ecological feedback effects of economic activity on the economic system, which are how the ecosystem provides the economic system with dynamic physical constraints and potentials.

- Inclusion of qualitative development and change, calling for a detailed description of sectoral interactions and of decision and behavioral processes. (Clearly, uncertainty about social and technological processes makes it very difficult to include such qualitative elements.)

- Inclusion of production and welfare elements, which means both a modeling of the economic structure and an evaluation of the output (including also an evaluation of welfare derived from the nonproductive use of the natural environment); in general, both potential and actual, productive and nonproductive uses of the environment are to be modeled.

Sustainable development is concerned with evolution over a long time period, focusing on stability issues and especially structural changes-that is, changes that result in qualitatively different characteristics of states or behavior of the system under consideration. Clearly, models for sustainable development should be dynamic in any case (see Smith 1977). Some structural changes may be generated endogenously by a model. Mathematical theories of chaos and bifurcation, for example, have shown that simple dynamic models can generate behavior with changes in qualitative characteristics of states (see Baumol and Benhabib 1989; Nijkamp and Reggiani, forthcoming). But most structural changes result from forces from outside a model, because they are uncertain in their nature and characteristics. In modeling terminology, structural changes may emerge in the following ways:

- Time paths may include nonsmooth or discontinuous parts as a result of reaching boundaries imposed by model constraints.

- The parameters of a system of dynamic equations may change and give rise to different qualitative behavior (for example, the number or character of equilibria may change).

- Relationships and variables may be deleted from or added to the model at hand, or the functional form of a relationship may change.

- Stochastic specifications may generate time paths with sudden changes in the value of variables; in the case of small disturbances, this also shows a high sensitivity of model behavior to parameter or initial stock values.

Clearly, it is possible to use dynamic models for RSD in a way that anticipates various-sometimes less probable-changes, for example, by combining several scenarios with simulation models. But real uncertainty about processes leading to structural changes and about changes in qualitative characteristics in the system means that it is hardly possible to overcome these problems, as this is essentially a consequence of limited knowledge about real-world processes. 
Especially the complicated pattern of interactions within and between economic and ecological processes calls for a detailed description. Indirect, feedback, nonlinear, time-delayed, and other kinds of relationships can be dealt with most appropriately in a formal logical framework. Simulation models are especially suitable for incorporating many theoretically and empirically obtained results of partial studies. In that sense a model provides a tool for obtaining many valuable insights, which can be tested and improved. Moreover, with inclusion of uncertainty in specification and use of models, one may obtain more quantitative, testable, and reliable estimations than an intuitive reflection on relationships between uncertainty and indicator values (for example, with simulation metaregression techniques; see Law and Kelton 1982).

Most dynamic (multi)regional models are based on programming, simulation, or analytical techniques. Most modeling approaches use only a single technique. The shortcomings of each technique can be compensated for by merging multiple techniques in a coherent combination. For example, Lonergan (1981) proposed combining programming models with simulation models. The simulation model was used in his framework to describe the ecosystem being controlled for economic purposes. An optimizing module was used to include normative aspects (that is, maximizing total added value of regional activities), while it received data from the simulation model to determine the right-hand sides of its constraints. In an iterative way, the optimum of the objective constrained by the ecological systems model and the requirements then could be reached.

Comprehensive models (that is, multidisciplinary, integrated, economicecological models) offer many opportunities for dealing with the requirements and demands posed for RSD issues. Integration may refer here to modules/ disciplines, techniques/models, and aggregation levels. Some authors propose a combined use of programming, econometric, and input-output models (see, for example, Isard 1986). Boyce $(1988$, p. 6) has stated in this context that "we should be seeking to integrate our theoretical concepts into more comprehensive model formulations."

It is an interesting exercise of course to design a general conceptual RSD model (see van den Bergh and others 1990), but in the context of our study we have limited ourselves to a general discussion of relevant RSD issues (and relevant models), followed by a set of concrete case studies. Thus, we move on to illustrate our ideas on the basis of three RSD case studies.

\section{Vi. Case Study A: The Peel Area in the Netherlands}

This section describes a first illustration of RSD analysis. The Peel area in the southeast Netherlands has been selected for a pilot study on RSD because of the intensive-and problematic-interactions between the natural resource base and economic activities there. The Peel region is situated on relatively high sandy soils and includes two hydrological systems divided by a faultline. Until the nineteenth century the area was an almost impenetrable marsh, dominated by peat moss. But two centuries of human influence have brought extensive drain- 
age and large-scale extraction of peat, which have created land for agriculture and forestry. This process has left only small pieces of the original natural system, such as the Groote Peel and the Maria Peel. These two natural fen areas are situated in an area in which intensive cattle farming and mixed agriculture are the dominant users of the land.

Most farmland in the Peel areas is drained each spring, lowering the water table to allow machines to work the land and cattle to enter pastures early. During the summer, when recharge of the aquifer itself is limited because of the spring drainage, shortfalls in soil moisture are circumvented by using irrigation sprinklers to pump from reserves of groundwater. Groundwater extraction for agriculture is shallow and widespread, whereas that for municipal supply occurs at a small number of sites and involves deeper extraction. The last few fens and marshes are threatened by dropping water tables. The intensive cattle farming practice causes large emissions of ammonium. Nearby forests and fens have suffered from various forms of ammonium-related damage. The high loads of nitrogen cause changes in the regional heathland by giving grassy vegetation a competitive advantage. Excess manure is spread over both pasture and cropland, leading to relatively high levels of soil nitrate, much of which leaches to lower strata and the groundwater aquifer. RSD thus is at stake in this region.

The most important interest groups in the region are the farmers, the drinking-water companies (representing also household interests), the tourist industry, the commercial forest owners (the State Forestry Service and private owners), and the nature conservation lobby (including the state as the owner of the national park de Groote Peel).

The renewable natural resources demanded by the regional and national interest groups are clean groundwater; clean air; vital and productive commercial forest; diverse and vital national park communities; and land for agriculture, development, protection of natural communities, and urban development. The Peel region's natural resources are used as goods-that is, groundwater for drinking and irrigation, timber for paper and pulp. The ecosystems perform services in the form of outdoor recreation and nature conservation, and they assimilate surplus ammonium and nitrate from nature. Hence, there are various questions and conflicting issues regarding the sustainability of land use in this area. And, clearly, the identification of critical success factors is crucial for RSD policies.

Sustained resource use in the region forms the starting point of our analysis. Economic activities are taken into account insofar as they influence (or are influenced by) these resources. Consequently, the regional boundaries were determined primarily by ecological and geographical criteria, based on the groundwater basin around the Peel-fen reserves. The renewable natural resources central to this study are groundwater, forests, and natural vegetation. The issues associated with these may be summarized as follows:

- High water tables, sandy soil, and nutrient-poor conditions have led to the development of unique ecological communities. 
- Widespread drainage of the land and multiple use of the groundwater resource (for irrigation as well as municipal supply) have lowered the water tables.

- Agricultural activities that use fertilizers intensively and that result in increasing production of manure are causing nitrate enrichment of the groundwater, affecting the remnant vegetation, and decreasing the suitability of the groundwater for human use.

- Air pollution is also causing acidification of soils, with effects on the natural vegetation as well as on forests.

In an RSD analysis, the economic sector also has to be considered. Economic activities that are directly dependent on the groundwater resource include agricultural and municipal water supply. Other activities in the region are timber production, recreation, and nature conservation. Agriculture especially contributes significantly to regional income. For some activities a further subdivision is useful. For example, timber production is based on two tree species-pine and Douglas fir, both of which are produced in plantations. Agriculture includes livestock rearing (cattle, pigs, and poultry) and crop cultivation (for livestock and human consumption). Livestock rearing can be intensive (for example, bioindustry for meat and egg products) or extensive (for example, dairy and meat). The spatial distribution of activities in the region also affects their interactions and relationships with available resources. For example, groundwater extraction for agriculture is shallow and widespread, whereas that for municipal supply occurs at a small number of sites and involves deeper extraction.

The central focus of this case study is on the relationship of the region's SRUs to its economic activities, with a view to identifying the critical success factors for RSD. Multiple use is a prominent feature and a source of conflict, because allocation of a scarce resource among users involves tradeoffs. For example, economic activities are not the only users of groundwater, and groundwater is also crucial for the regeneration of wetland communities.

In view of the foregoing observations on RSD in the Peel area, the most important critical success factors associated with these resources may be summarized as follows:

- Maintaining the groundwater level. High water tables have been a major feature of the Peel and, together with the sandy soil and generally nutrientpoor conditions, have led to unique ecological communities. Widespread drainage of the land and increasing use of the groundwater resource (for irrigation and municipal supply) have lowered these water tables.

- Curtailing nitrogen pollution. Agricultural activities using fertilizers and producing excessive amounts of manure are causing nitrate enrichment of soil and groundwater, leading to changes in the remnant fen and heathland vegetation as well as to decreasing suitability for human consumption. Agriculturally originated ammonium emissions, in addition to nitrogen and sulphur oxides from various sources within and outside the region, affect the vegetation directly and contribute to the acidification of soils, resulting in changes in the natural vegetation and in decrease of forest vitality. 
- Regulating competitive demand for land. The present and expected future demand for land by the agricultural sector, nature conservation, and urban (including residential, industrial and tourist attractions) interest groups is conflicting and less sustainable.

The analysis of regional system interactions in this area has resulted in the design of an exploratory dynamic simulation model (see van den Bergh and Nijkamp 1990). The submodules describe groundwater, nitrates, forestry and natural vegetation, agriculture, and regional economic activities. The submodule that describes the economic activity records profits over time for each sector on the basis of developments of quantities, costs, prices, and technology. The time paths for quantities are for most sectors based on changes in production capacity, except for recreation, where demand for recreational activity determines the quantity. The development of the economic system is to a large extent determined by exogenous variables, for which the time paths were chosen on the basis of a relevant development scenario. The fact that a relatively low number of interactions between different sectors is modeled is because of the small size of the region. Models that include many interactions between sectors (for example, interindustry supply, or competition on factor and final markets) usually have an economywide rather than a regional orientation (see Vincent 1982). The global interrelationships between the modules are listed in figure 1 (for a full description, see van den Bergh and others 1990). These indicator variables were chosen for the assessment of RSD:

- Value added in the region

- Costs of measures

- Nature conservation value

- Recreational attractiveness

- Groundwater quality with respect to concentration of nitrates

- Air quality with respect to concentration of nitrates and ammonia in the air

- Stock of groundwater

- Stocks of vegetation and forest.

The indicator for nature conservation value is based on vegetation areas. Recreational attractiveness is based on economic facilities, natural amenities, and disservices (arising from economic activities).

The spatial scale of the model distinguishes between two subregions, the national park de Groote Peel and buffer zone, and the rest of the region. The indicators selected to provide relevant information for the judgment of RSD in this area are as follows:

- Yearly value added in crops, livestock, extracted groundwater, forestry, and timber

- Total recreational (amenity) value

- Cost-benefit ratio of pollution control measures

- Yearly average ambient air concentration of ammonium $\left(\mathrm{NH}_{3}\right)$

- Yearly average nitrate concentration in groundwater $\left(\mathrm{NO}_{3}\right)$. 
Figure 1. Modules and Relationships of the Peel Model

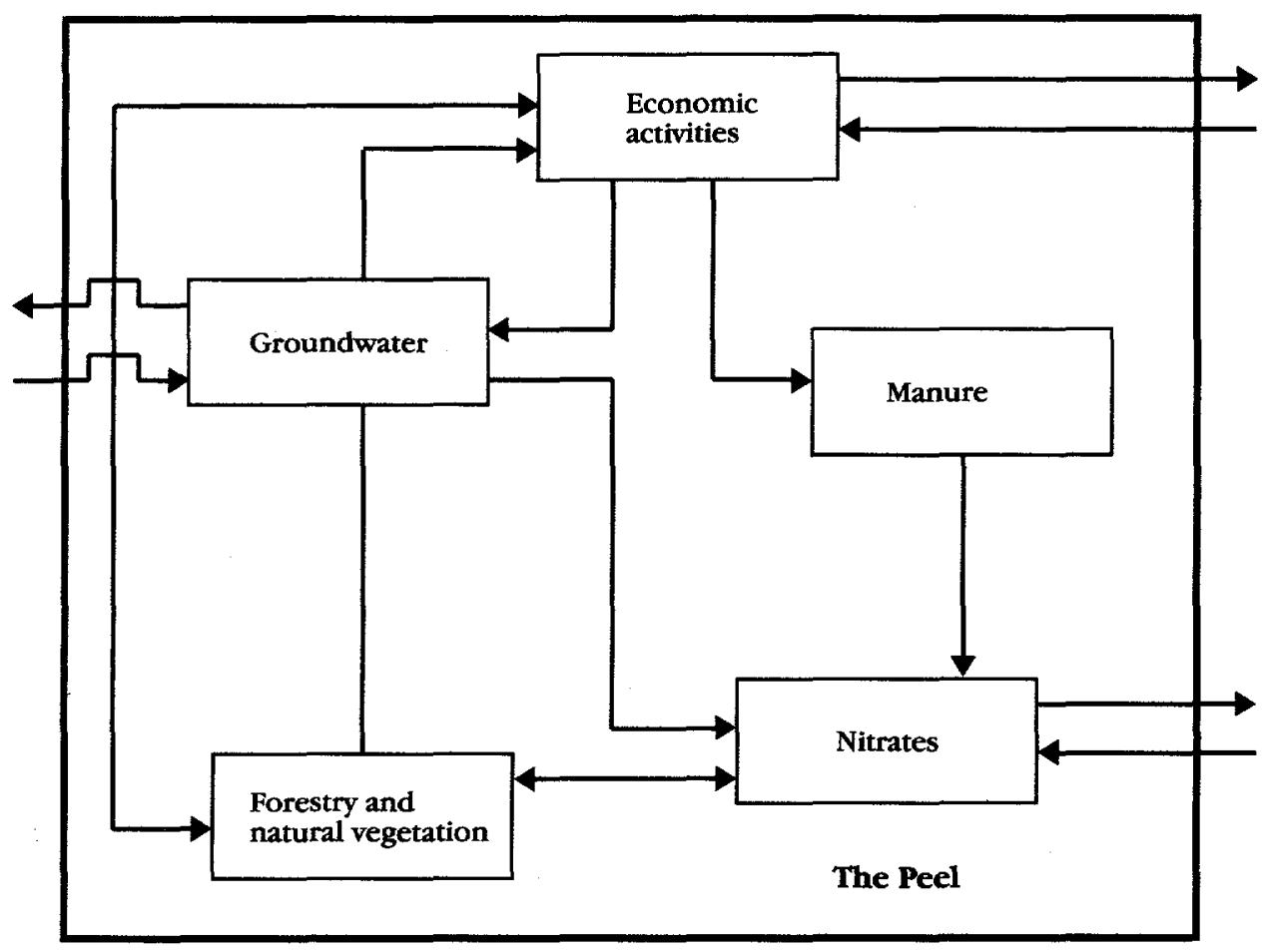

- Land area classified as urban, agricultural, and natural

- Community diversity in the national park.

As mentioned above, external developments and policy choices will be incorporated via scenarios. Each scenario that is used for a simulation run has effects that are evaluated regarding their RSD via the indicators listed above. Effects may be compared with standards and may lead to inferences about acceptance or rejection of the relevance of the scenario used for RSD. The scenarios are determined by choices for both exogenous and management variables. To limit the number of scenarios, we have identified some plausible scenarios consisting of a set of related changes in variables. The time horizon of the scenarios is fifty years with $1980-81$ as base years; the time solution is given in years. The model has been run for each of the six scenarios mentioned hereafter. Each scenario description is followed by a brief evaluation of the time paths of indicators.

\section{Scenario 1: Business as Usual}

The stock of grazing cattle declines from 1980 to 1985 and remains constant during the rest of the simulation period. The stock of feedlot cattle increases by 10 percent for each period of twenty years. Population will increase by 9,000 per decade for the period 1980-81 to 2000 (trends are extrapolated after that 
year). Imports of nitrogen from outside the Peel region and sulphur oxide emissions decline; nitrogen oxides decrease by 30 percent and $\mathrm{SO}_{2}$ emissions by some 45 percent after fifteen years.

The results in figure 2 indicate that in this scenario major changes are expected after fifteen years. The trend toward grassification of heathland is somewhat delayed. An improvement in the air quality index results, implying that the forest volume of alders increases significantly and that the downward trend for douglas firs is stopped. Ammonia and nitrate emissions increase slowly, and the concentration of nitrates in deep groundwater is somewhat higher than under the steady state. After fifteen years, total value added increases as a result of forest improvement, an increase in recreational revenues resulting from an improved natural environment, and an increase in feedlot farming.

\section{Scenario 2: No Import of Sulphur Dioxide and Nitrogen Oxides}

This scenario is based on the same assumptions as the business-as-usual scenario with the exception of imported sulphur dioxide and nitrogen oxides. These emissions are set to a level of zero after fifteen years to assess the impact of foreign policies and the possibilities for regional policy. It also can be seen as an assessment of interregional tradeoffs.

Compared with the business-as-usual scenario, soil $\mathrm{pH}$ and air quality appear to improve more dramatically (figure 3 ). It is significant that the trend toward grassification of heathlands would be reversed. Forest improvement, for both Douglas fir and alders, would be strengthened. Value added appears to improve because of the improvement in forestry and recreational value.

\section{Scenario 3: Present Environmental Policy}

On the basis of the business-as-usual scenario and the present government policy of controlling the use of manure on land, a contemporary environmental policy scenario with fairly stringent regulations is created. The simulation results in figure 4 show that after fifteen years a significant decline in ammonia emissions occurs. The downward trends in both alders and wet heathlands are clearly reversed, and the share of grassland decreases significantly after approximately twenty years. The improvements in forestry and natural vegetation, already observed under the business-as-usual scenario, are strengthened. Net present value, apart from the "hiccup" after fifteen years caused by a sudden increase in yields not yet counterbalanced by manure disposal costs, eventually rises toward a higher level.

\section{Scenario 4: Present Environmental Policy plus Ammonia Scrubbing}

This scenario is the same as scenario 3, except that now all feedlot stables are provided with biofiltration equipment after fifteen years. Figure 5 shows that compared with the present environmental policy scenario, the improvement in 
Figure 2. The Business-as-Usual Scenario for the Peel Area
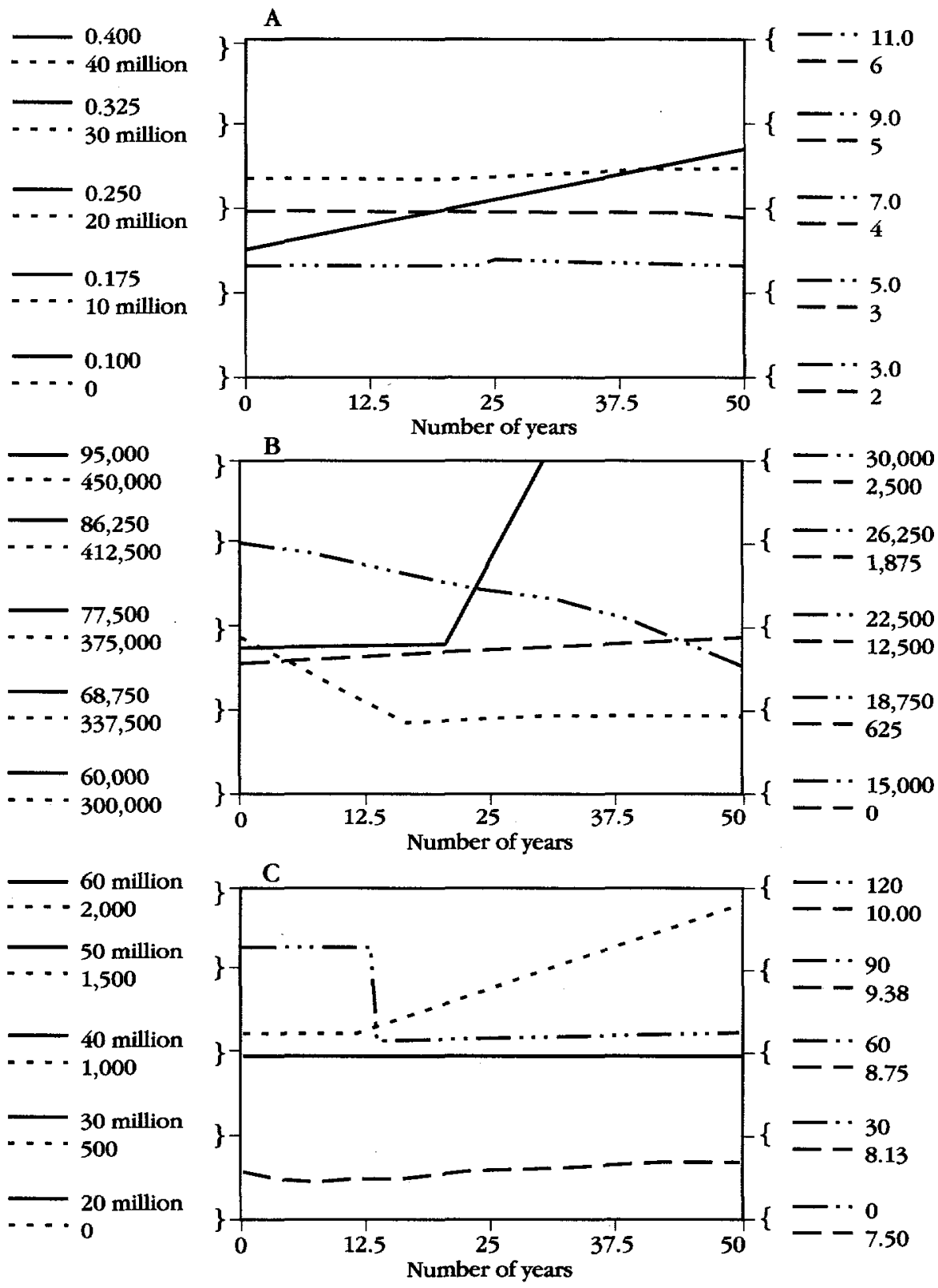

Key: In graph A, - is the concentration of nitrates in the deep groundwater reservoir (in kilograms per millions of liters); - - . is the total ammonia release from manure (kilograms); - - is the $\mathrm{pH}$ level in the soil; and - - is the volume of surface groundwater (millions of liters). In graph $B$, the lines denote the stocks of natural vegetation; - alders, - - Douglas fir, - - wet heathland, and - - grass (all in cubic meters per hectare). In graph $\mathrm{C},-$ is the stock of deep groundwater (millions of liters); - - - is an indicator for the nature conservation value based on all vegetation types; - - . is a general index of air quality; and - - is the total value added of regional economic activity (in billions of Dutch guilders). 
Figure 3. Scenario Featuring no Import of Sulfur Dioxide and Nitrogen Oxide for the Peel Area

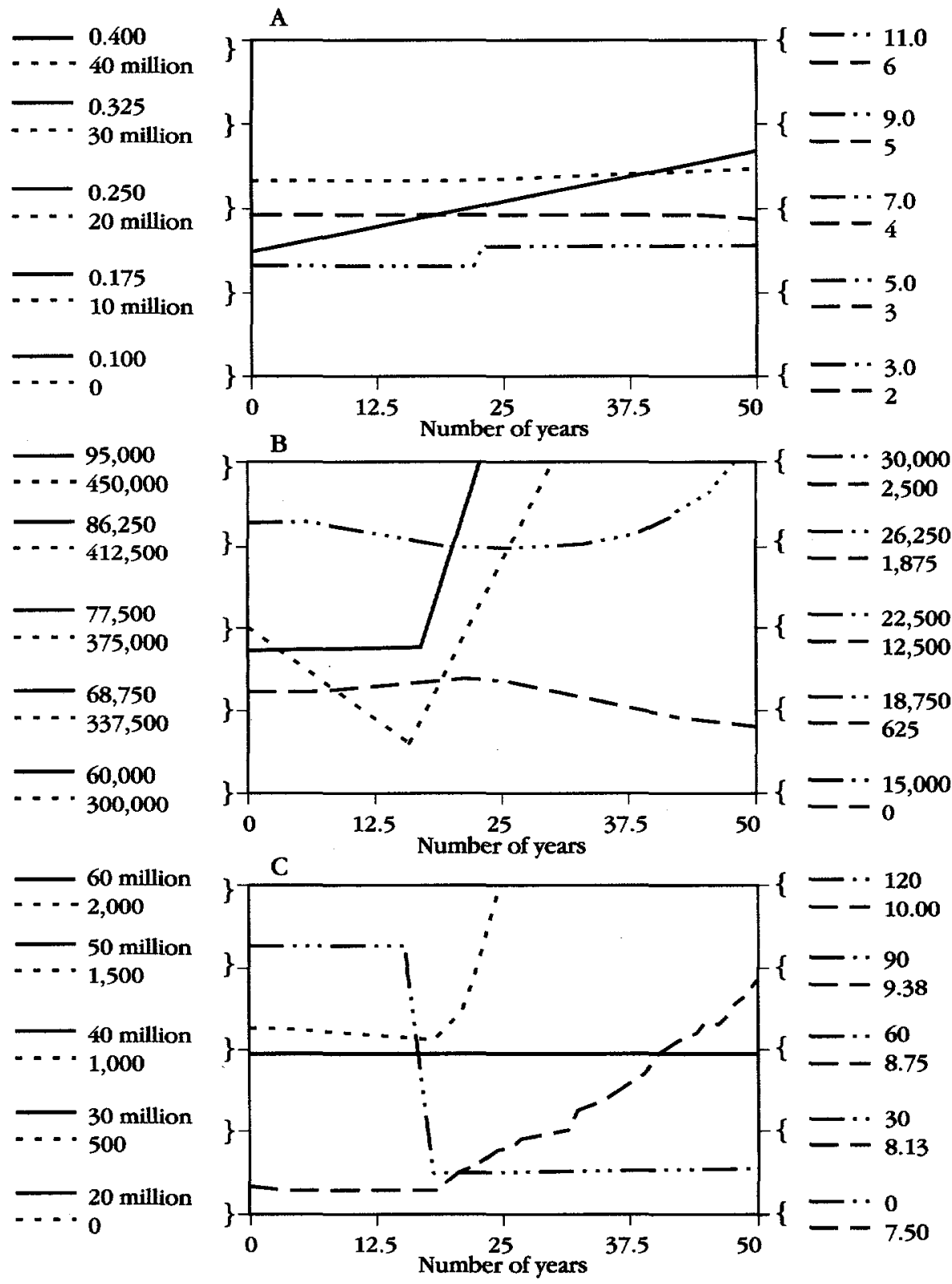

Key: In graph A, - is the concentration of nitrates in the deep groundwater reservoir (in kilograms per millions of liters); - - - is the total ammonia release from manure (kilograms); - - is the $\mathrm{pH}$ level in the soil; and - - is the volume of surface groundwater (millions of liters). In graph B, the lines denote the stocks of natural vegetation; - alders, - - - Douglas fir, - - wet heathland, and - - grass (all in cubic meters per hectare). In graph $\mathrm{C}$, - is the stock of deep groundwater (millions of liters); - - - - is an indicator for the nature conservation value based on all vegetation types; - - .. is a general index of air quality; and - - is the total value added of regional economic activity (in billions of Dutch guilders). 
Figure 4. Scenario Following Present Environmental Policy for Peel Area

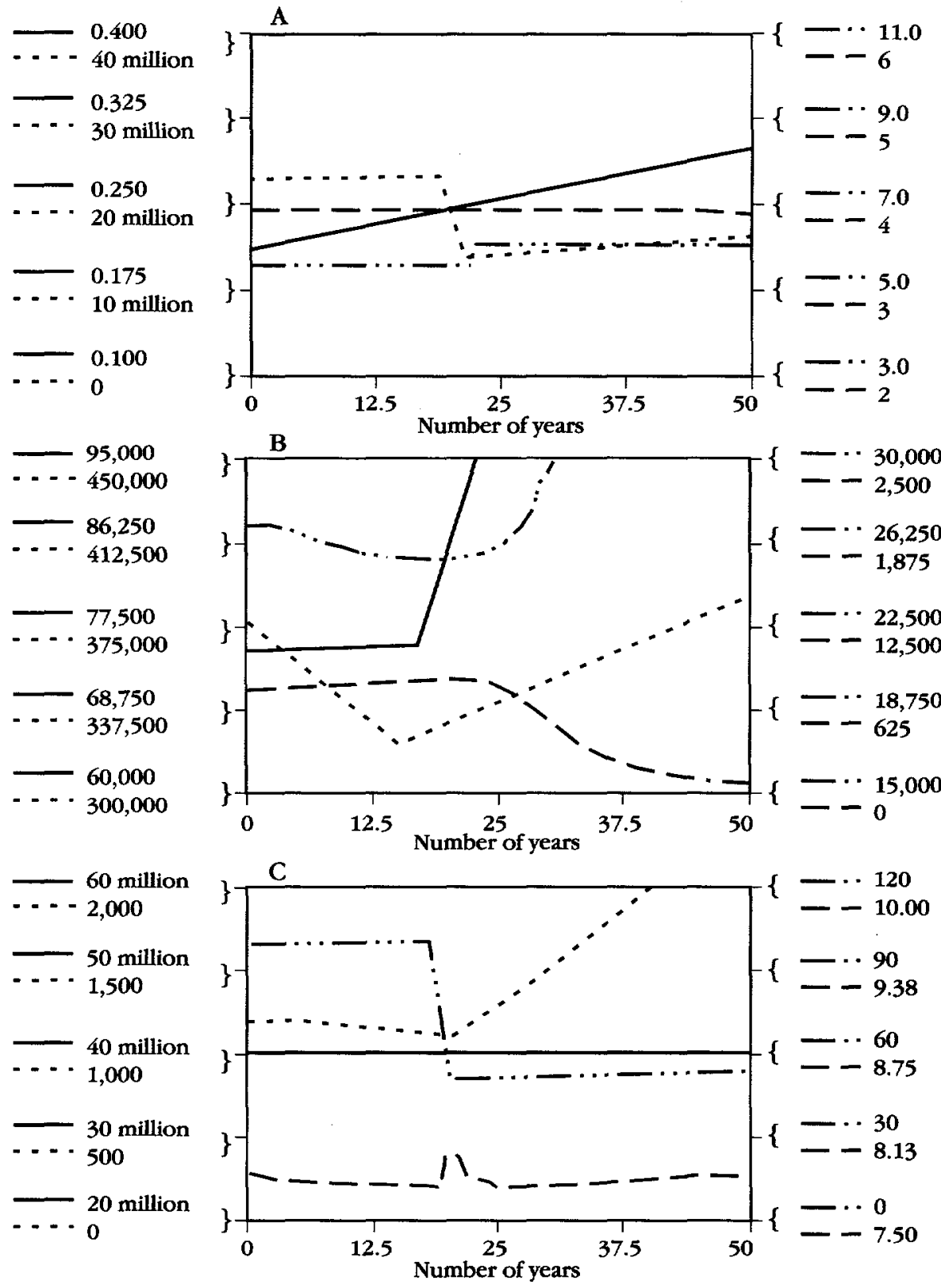

Key: In graph $\mathrm{A},-$ is the concentration of nitrates in the deep groundwater reservoir (in kilograms per millions of liters); - - - is the total ammonia release from manure (kilograms); - $\cdots$ is the $\mathrm{pH}$ level in the soil; and - - is the volume of surface groundwater (millions of liters). In graph $\mathrm{B}$, the lines denote the stocks of natural vegetation; - alders, - - - Douglas fir, - - wet heathland, and - - grass (all in cubic meters per hectare). In graph $\mathrm{C},-$ is the stock of deep groundwater (millions of liters); - . - . is an indicator for the nature conservation value based on all vegetation types; _ - . is a general index of air quality; and - - is the total value added of regional economic activity (in billions of Dutch guilders). 
wet heathland as well as the reduction in grassland is postponed, although an increase in Douglas firs is reached sooner. This is caused by an increase in nitrate resulting from biofiltration. Total value added does not alter much in terms of size, but it does so in terms of composition. The costs of biofiltration have a significant impact on the value added in the feedlot industry. This is counterbalanced by the increase in recreational demand and timber production.

\section{Scenario 5: Maximum Technical Efforts}

This is the same as scenario 4, except that more stringent technical standards are required. The standards are based in this scenario on the uptake of minerals by vegetation and are approximately twice as low as the governmental standards for 1995. Accordingly, we have reduced the application of manure on land by 50 percent compared with scenario 4 .

Figure 6 indicates that ammonia emissions already are clearly lower after ten years. This has a beneficial impact on natural vegetation and forestry, where recovery will take place sooner. The cost of this action, however, has to be borne earlier, especially by feedlot farming. Total value added in the region is not significantly affected.

\section{Scenario 6: Land Use Shifts}

These shifts are based on the business-as-usual scenario with the exception of the area allocated to arable land. This was reduced by 50 percent compared with 1980. The area of land allocated to forestry and natural vegetation increases by approximately 125 percent, with the exception of grassland area, whose size is constant.

The volumes of natural vegetation are significantly higher (see figure 7) than under the first scenario. Also, because of less crop irrigation, the stock of surface groundwater is higher, which positively influences natural vegetation. As can be seen from figure 7 , initially, total value added is some 25 percent higher, but then it drops and remains only slightly above the business-as-usual level.

Further research is required to improve the empirical robustness of the model, with a special emphasis on policy strategies. Some of the data would have to be improved in precision. Some equations require more reliable data to enable a realistic specification (for example, recreational amenity, hydrological processes, and output from crops as a function of fertilizer and groundwater use). The model also might be validated by means of a historical run to track historical data. Therefore, it is clear that for the time being the above results are mainly illustrative for RSD planning. Nevertheless, it is clear from the model experiments that the groundwater level, production of nitrogen, and conflicting demand for land in the area concerned may be regarded as critical success factors for a balanced policy regarding SRU of the Peel area. 
Figure 5. Scenario Following Present Environmental Policy for Peel Area but witb Addition to Feedlots of Biofiltration Equipment for Ammonia Scrubbing After Fifteen Years

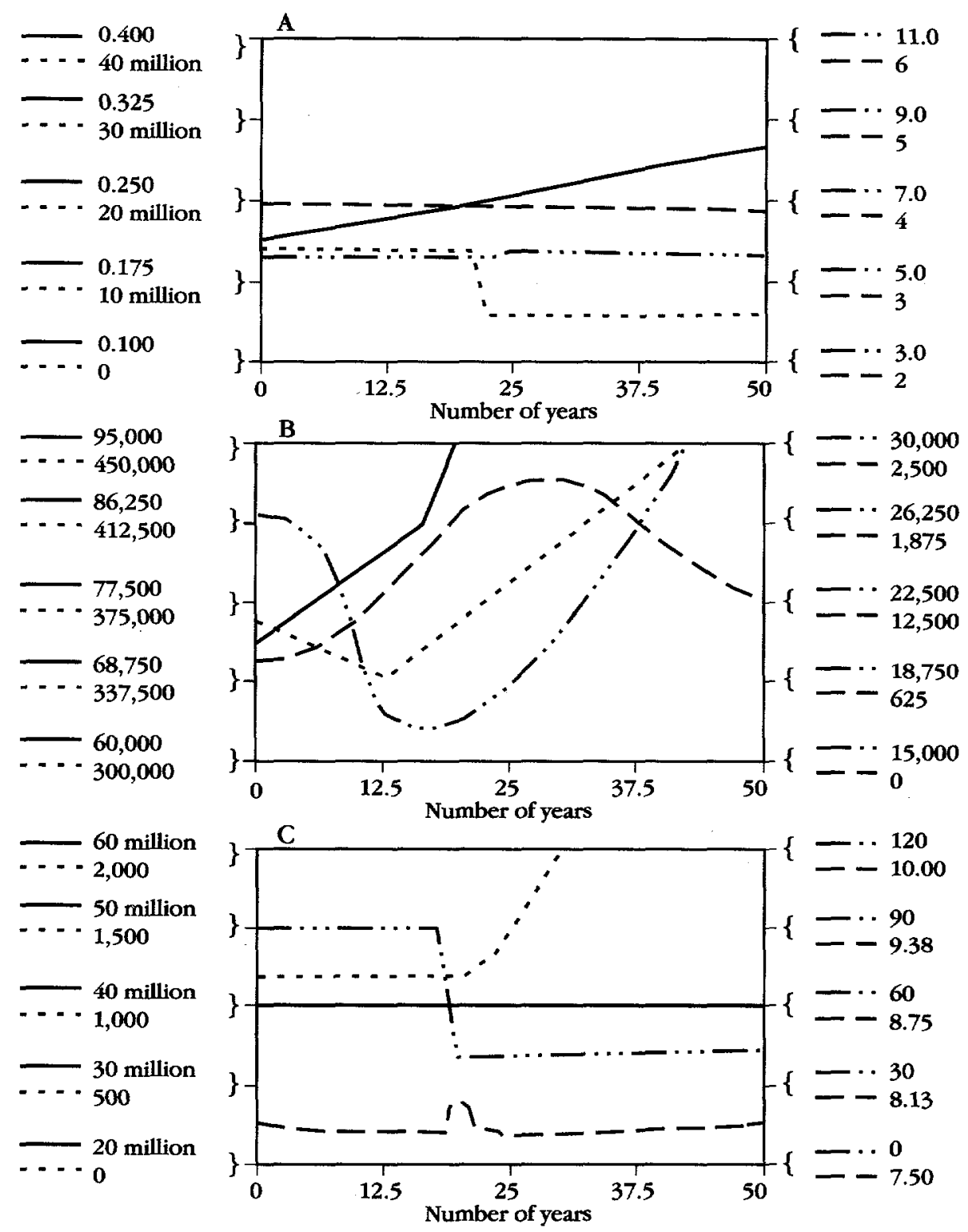

Key: In graph $\mathrm{A},-$ is the concentration of nitrates in the deep groundwater reservoir (in kilograms per millions of liters); - . - is the total ammonia release from manure (kilograms); - - is the $\mathrm{pH}$ level in the soil; and - - is the volume of surface groundwater (millions of liters). In graph B, the lines denote the stocks of natural vegetation; - alders, - - - Douglas fir, - - wet heathland, and - - grass (all in cubic meters per hectare). In graph $\mathrm{C}, \longrightarrow$ is the stock of deep groundwater (millions of liters); - - . - is an indicator for the nature conservation value based on all vegetation types; $-\cdots$ is a general index of air quality; and - - is the total value added of regional economic activity (in billions of Dutch guilders). 
Figure 6. Scenario Using Maximum Technical Efforts to Curtail Ammonia Emissions in the Peel Area

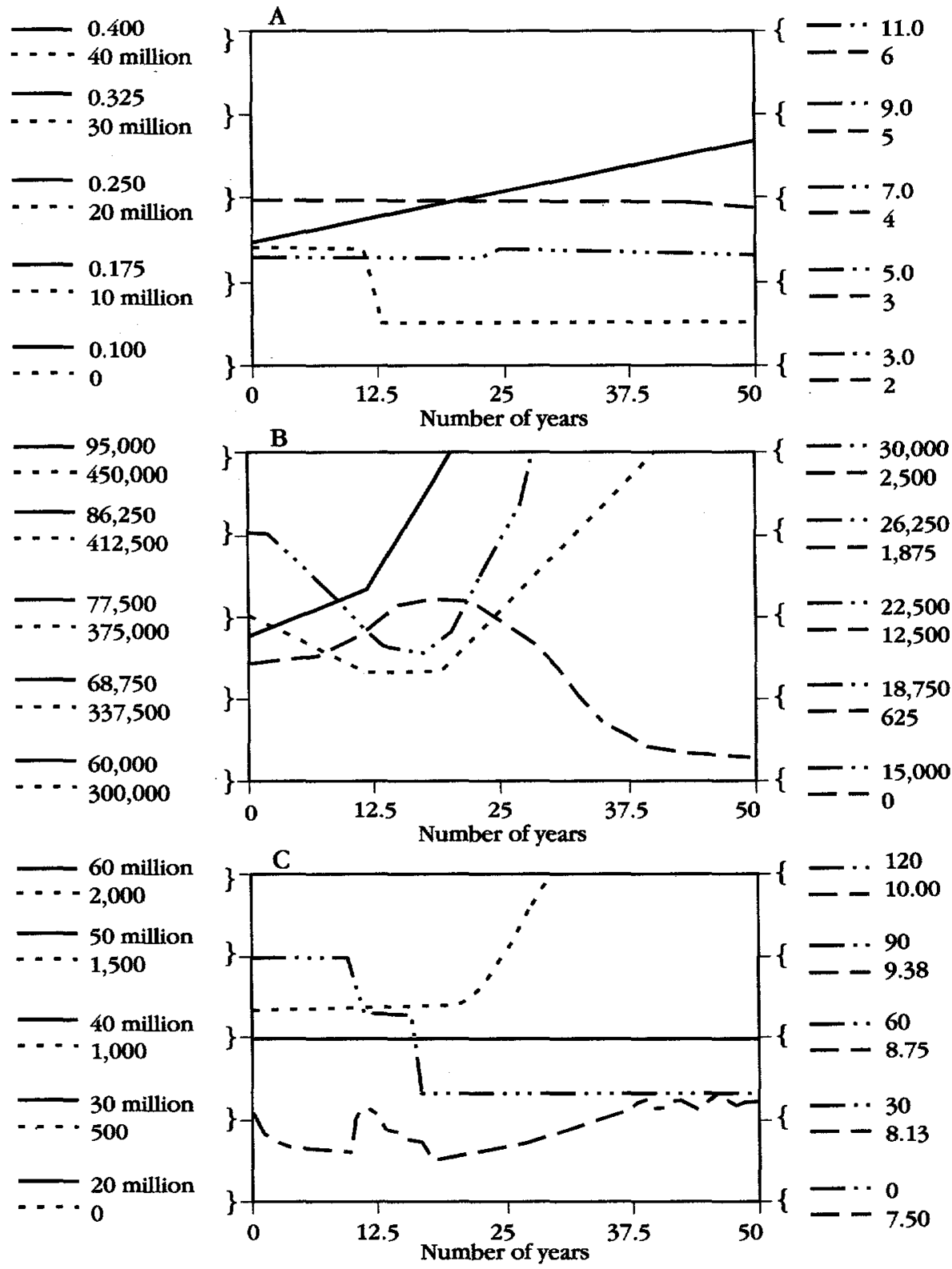

Key: In graph $\mathrm{A},-$ is the concentration of nitrates in the deep groundwater reservoir (in kilograms per millions of liters); - - is the total ammonia release from manure (kilograms); - - is the $\mathrm{pH}$ level in the soil; and - - is the volume of surface groundwater (millions of liters). In graph B, the lines denote the stocks of natural vegetation; - alders, - - - Douglas fir, - - wet heathland, and - - grass (all in cubic meters per hectare). In graph $\mathrm{C}, \longrightarrow$ is the stock of deep groundwater (millions of liters); . . . is an indicator for the nature conservation value based on all vegetation types; - - . is a general index of air quality; and - - is the total value added of regional economic activity (in billions of Dutch guilders). 
Figure 7. Scenario Postulating Shift in Land Use (Reduction in Arable Land) in the Peel Area

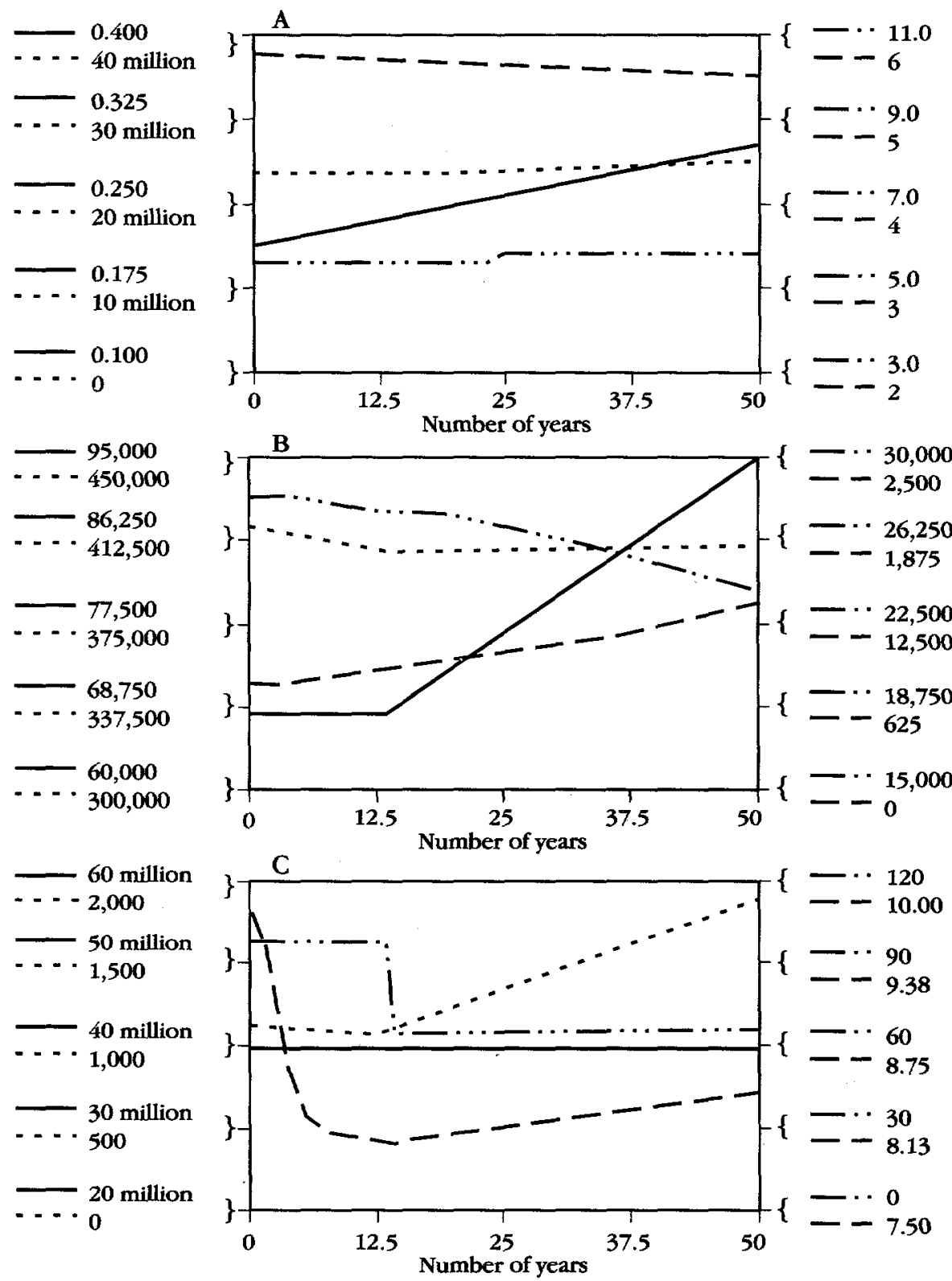

Key: In graph A, - is the concentration of nitrates in the deep groundwater reservoir (in kilograms per millions of liters); - . - is the total ammonia release from manure (kilograms); - $\cdots$ is the $\mathrm{pH}$ level in the soil; and - - is the volume of surface groundwater (millions of liters). In graph B, the lines denote the stocks of natural vegetation; - alders, - - - Douglas fir, - - wet heathland, and - - grass (all in cubic meters per hectare). In graph C, — is the stock of deep groundwater (millions of liters); . . . is an indicator for the nature conservation value based on all vegetation types; _ - .. is a general index of air quality; and - - is the total value added of regional economic activity (in billions of Dutch guilders). 


\section{Case Study B: The Sporades Islands in Greece}

The Sporades Islands form a complex of ecologically extremely important but vulnerable islands located off central Greece in the Aegean sea. The islands' geological, archaeological, and cultural value is very high. From an environmental viewpoint they are rich in vegetation. In general, the flora, fauna, and ornithology provide many interesting examples of unique wildlife. The surrounding sea hosts sea coral, dolphins, whales, and monk seals-the last a rare species that has been declining drastically in recent decades. New pressures from the tourist and fishery sector for increased exploitation of resources have led to severe conflicts with priorities of ecological balance and conservation. In search of a resolution of mutually conflicting growth trajectories, the Greek government, in cooperation with the European Community (EC) has established an international marine and terrestrial research center on the island of Alonnissos, and, as part of an environmental preservation policy, a strictly protected area has been designated in the Northern Sporades Marine Park (see Giaoutzi and Nijkamp 1990).

Recently a project commissioned by the EC has begun to design a planningoriented monitoring and information system and an operational strategic policy model. The aim of the model is to support management decisionmaking for the economic development of the islands and the marine park with surrounding areas. Using simulation experiments, a descriptive prototype systems model has been developed. The model uses a time horizon of twenty years, has a time resolution in terms of years, and is designed as a modular system using a socalled satellite principle (see Brouwer and Nijkamp 1988). Because the tourist and fishery sectors are the dominant factors in the stress on the ecosystem in the Sporades region, they are core modules in the integrated environmental model. The modular structure includes three parts (see figure 8 ):

- A regional economic submodel concentrates on the relatively large tourist sector and the fishery sector. The original economic structure of the island, agriculture, is included, as are the governmental services and utilities (although in a more elementary way). Also, simple models for population, tourism, housing, labor and land markets, waste generation, and materials and financial balances are included.

- A marine submodel concentrates on the dynamics in the food chain (the top of which is formed by the monk seal) and describes the behavior of passing dolphins and whales, as well as the activities of fishermen.

- A terrestrial submodel is developed, including a land use model, a groundwater model, and a vegetation-fauna model. This submodel has many interactions with land use development and erosion processes.

Some indicators for RSD in the Sporades are:

- Tourist services and accommodation

- Regional capital (for example, fishing vessels, water pumping capacity) 
Figure 8. Structure of the Sporades Model

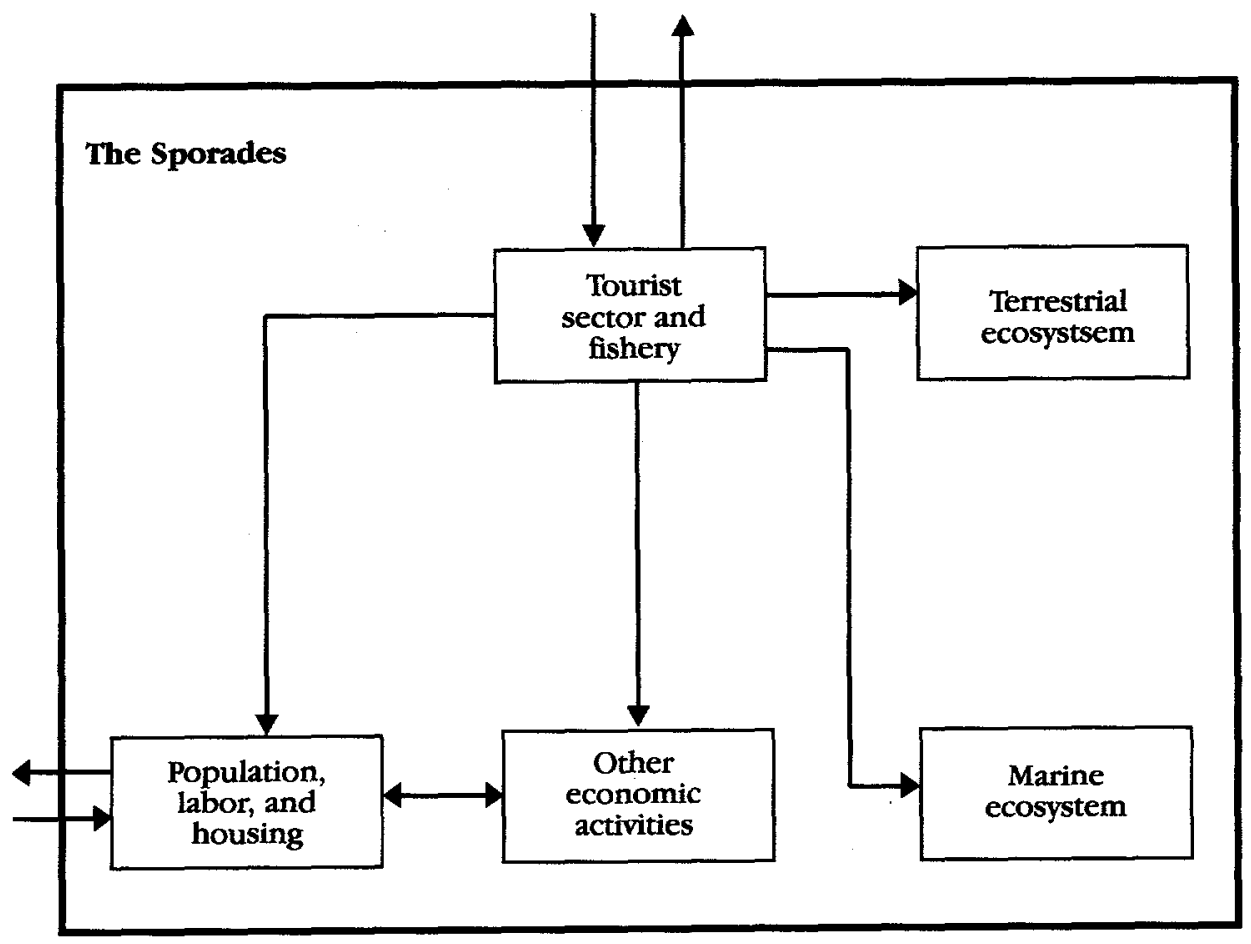

- Water pumping capacity

- Regional employment

- Income per capita

- Congestion, noise, and waste dump

- Ratio of profits in the tourist sector to profits in other sectors

- Stocks of terrestrial vegetation and animals

- Stocks of sea animals

- Aquifer stock

- Ratios of pumping rates and fishing rates to the stock levels of aquifer and fish, respectively.

The RSD issues on the Sporades are described in the prototype model by means of a stock-flow structure. The model is formulated with a spatial resolution of biological zones, based on the spatial coverage of the islands and the marine park, and the spatial aspects of fishery and tourism. The spatial subdivision includes the main islands of Skiathos, Skopelos, and Alonnissos. In a later stage of the research the time resolution will be changed to seasons, because the dominant activities on the islands have a seasonal pattern.

The simulation model for the Sporades has a strict modular design. It has an 
extensive economic module, in which economic activities, income, and investments are linked to land use, fishery, and tourism. Tourism is also connected with land use, the marine ecosystem, and the terrestrial system, as well as with fishery. The model has a detailed description of all these components with a special focus on the potential conflicts (and their resolution) between different competing activities.

The following factors appear to act as critical success factors in environmental planning and management in this area:

- Managing the development of tourism. Tourism increases both the level of welfare and the environmental pressure and plays a critical role in RSD for the Sporades.

- Maintaining the qualitative and quantitative aspects of the aquifer. The availability of water is of crucial importance for the economic development and the ecological quality of these islands. However, a proper balance is hard to find.

- Limiting the spatial transfer of economic revenues on the islands. If the Sporades are only seen and used as a source of benefits for external investors, their ecological and economic base will be eroded, and RSD will not be attained.

Fairly extensive fieldwork had to be undertaken, because no reliable data base for these islands was available. A prototype model has been developed that includes in a detailed manner the indicators sketched above. A set of simulation experiments has been undertaken to test the validity of model specifications and the sensitivity of the data set. Some first policy scenarios have been developed, based, for example, on land use zoning, quota systems for the fishery sector, and new agricultural activities. In these exercises, use is also made of geographic information systems to present detailed impacts on land use and the terrestrial system on the islands.

\section{Case Study C: Rural Development in Botswana}

Despite much effort, the income gap between the developed and the developing world has not diminished. Furthermore, environmental problems have been persistent, both at worldwide and at local and regional levels. In many developing countries we are witnessing resource depletion such as deforestation and desertification. Short-term interests arising from subsistence and survival problems are often eroding balanced long-term resource management. Thus, sustainable development is often an illusion. In a case study on Botswana, Arntzen (1989) thoroughly investigated the possibilities of RSD.

The starting point of RSD analysis here was a blend of the ecological complex approach (an abstract model of relevant relationships within and between various modules in a regional system that are relevant from a sustainable development perspective) and Wilkinson's (1973) ecological theory of economic development (including natural resources and negative feedbacks of human activities 
on the environment). The imbalance between sustainable resource use and human activities may emerge from various factors, such as socioeconomic stratification, external factors, market imperfections, and other development constraints.

The current information on Botswana is hardly sufficient for proactive policymaking because the available data do not include a direct valuation of various natural resources (and hence no representation of the actual costs of the resource use), whereas in some cases (for example, timber) even implicit zero prices are assigned. This unfortunate situation, which favors unsustainable resource use, is codetermined by the communal rights to many resources in Botswana. Thus, the property right system works to the detriment of RSD in Botswana. A necessary condition for improving this situation would be to set up an up-to-date system of regional resource accounts.

Arntzen's (1989) study focused on RSD in Botswana in an attempt to identify the extent and nature of land pressure, the adjustment strategies used by people, and the impacts of socioeconomic strata and external factors. Particular attention was given to land pressure in various regions in Botswana-Southeast district, Kgatleng district, Central district, and Palapye.

Land pressure in various regions in Botswana is fairly high, particularly in small districts, given the available technology and the production constraints in such semi-arid regions. Land pressure is particularly important in case of overstocking.

The critical success factors in coping with the problems of land pressure appeared to be the following:

- Controlling population growth in the areas concerned

- Ensuring balanced livestock development

- Controlling land alienation, mainly in smaller districts

- Controlling technological developments and related policies regarding boreholes.

The analysis was based not on a formal RSD model but rather on extensive fieldwork and statistical data analysis. Particular attention was given to the adaptation mechanisms in situations of high land pressure, such as expansion of the resource base, intensification of existing activities, economic diversification, and population adjustments. Also the impact of dislocating factors for farmers was examined more thoroughly-that is, socioeconomic stratification and external influences (for example, labor market developments and government policies).

It turned out that there was a significant variation in regional adaptation and behavioral responses. Thus, RSD is not a concept that can be handled by means of a single measuring rod. It requires a simultaneous consideration of relevant welfare considerations (including ecological indicators) from the viewpoint of a balanced development in specific regional situations. 


\section{CONCLUSIONS}

Ecologically sustainable economic development has become a policy issue of major significance. This paper has focused attention on sustainable development in a regional context. Conceptualizing and analyzing sustainable development is clearly important at a regional level. Various advantages of a regional approach have been spelled out, for example, in relation to regional causes and effects of environmental problems, the local character of economic processes, interregional interactions, and the possibility of operationalizing sustainable development on a regional scale. Sustainable resource use was presented as an important element of RSD.

In our analysis of RSD we started with a stocktaking of the internal characteristics of the region, its interactions, and relevant external (global) phenomena. In discussing a regional resource base we argued that the present and potential dependence of regional activities on the resource base as well as the specific characteristics of the resource base should be assessed. With regard to the use of models, we mentioned the main problems in the context of RSD issues, with a particular emphasis on critical success factors. Finally, we presented three case studies in which some of the general discussions were illustrated, indicators for RSD were mentioned, and critical success factors were identified. In one case study, on the Peel area, we presented simulation results for scenarios including different, but realistic, future options with regard to continuation of present level of cattle breeding, environmental policy, technologically feasible emission levels, and land use shifts.

Various lessons and issues for further research can be drawn from the above exposition. RSD refers to a systemic view of interacting regions of our world economy, not only in terms of economic linkages but also in terms of environmental interactions. Thus space and time are the two essential dimensions of RSD.

The openness of a spatial system evokes the question of environmental sacrifices in space and time. The issue of the substitutability of environmental decay (in other periods of time, in other regions) is at stake here; the related concept of weak and strong sustainability requires further exploration on the basis of a thorough investigation of underlying welfare concepts (and associated collective welfare functions).

In order to find a balanced equilibrium of resources in space and time, much attention would have to be given to regional resource accounting. Efficiency, equity, and externality aspects of resource use can then be given due emphasis, while attempts at valuing unpriced resources may provide a sound basis for project appraisal. Geographic information systems may be helpful here to visualize all relevant policy aspects.

Environmental externalities should be looked at not only from the viewpoint of market failures (or signal failures) but also from the viewpoint of intervention 
(or response) failures. In many cases governments-in an attempt to cope with environmental deterioration-have misjudged the causes of such decay and have even aggravated the original conditions (witness the many failures in transport policy worldwide, for example). Thus, a closer analysis of the costs and remedies regarding both signal and response failures would be desirable. Internalization of social costs then might also be considered at an early stage of decisionmaking-that is, in the design phase rather than ex post, when all decisions have already been made. RSD also calls for integrated community impact analysis and related project appraisal methods (for example, in the form of multi-objective decision analysis and multicriteria analysis).

In the context of RSD, critical success factors refer to major focal points for policy intervention. Identification of such factors may induce proactive sustainability of policies. In the context of RSD planning, where regions are open, critical success factors also may be found outside the specific region.

As shown in this paper, simulation experiments leading to concerted evaluation procedures for RSD may be helpful analytical tools. Some experiments demonstrated in this paper have pointed out the value of simulation models for RSD analysis, particularly with a view toward identifying critical success factors in a balanced regional development.

\section{REFERENCES}

Archibugi, Franco, and Peter Nijkamp, eds. 1989. Economy and Ecology: Towards Sustainable Development. Dordrecht, Netherlands: Kluwer Nijhoff.

Arntzen, Jaap. 1989. "Environmental Pressure and Adaptation in Rural Botswana." Ph.D. diss., Department of Economics, Free University of Amsterdam (Netherlands).

Bartelmus, P. 1986. Environment and Development. London: Allen \& Unwin.

Baumol, William J., and J. Benhabib. 1989. "Chaos: Significance, Mechanism, and Economic Applications." Journal of Economic Perspectives 3: 77-106.

Baumol, William J., and W. E. Oates. 1988. The Theory of Environmental Policy. Cambridge, U.K.: Cambridge University Press.

Boyce, David E., 1988. "Presidential Address: Renaissance of Large-Scale Models." Papers of the Regional Science Association 65: 1-10.

Brouwer, Floor M., and Peter Nijkamp. 1988. "Design and Structure Analysis of Integrated Environmental Planning Models." European Review of Agricultural Economics 15: 1-38.

Ciriacy-Wantrup, S. V. 1952. Resource Conservation. Berkeley: University of California Press.

Clark, William C. 1986. "Sustainable Development of the Biosphere: Themes for a Research Plan." In W. C. Clark and R. E. Munn, eds., Sustainable Development of the Biosphere. Cambridge, U.K.: Cambridge University Press.

Clark, W. C., and Ted Munn, eds. 1986. Sustainable Development of the Biosphere. Cambridge, U.K.: Cambridge University Press.

Collard, D., David Pearce, and D. Ulph. 1989. Economics, Growth and Sustainable Environment. London: Macmillan. 
Ewringmann, D., and K. Hansmeyer. 1980. "The Institutional Setting of Regional Environmental Policy." In H. Siebert, I. Walter, and K. Zimmermann, eds., Regional Environmental Policy. London: Macmillan.

Frey, René L. 1980. "Interregional Welfare Comparisons and Environmental Policy." In H. Siebert, I. Walter, and K. Zimmermann, eds., Regional Environmental Policy. London: Macmillan.

Giaoutzi, Maria, and Peter Nijkamp. 1990. "A Strategic Environmental Information System and Planning Model for Marine Park Development." Research Memorandum, Department of Economics, Free University of Amsterdam (Netherlands). Processed.

Isard, Walter. 1986. "Reflections on the Relevance of Integrated Multiregion Models." Regional Science and Urban Economics 16: 165-80.

Kairiukstis, Leo, ed. 1989. Ecological Sustainability of Regional Development. Laxenburg, Austria: International Institute for Applied Systems Analysis.

Klijn, Fred. 1988. Milieubeheergebieden (Environmental Management Areas). CML Information Bulletin 37. Leiden, Netherlands: Centrum voor Milieukunde Rijksuniversiteit Leiden.

Law, A. M., and W. S. Kelton. 1982. Simulation Modeling and Analysis. New York: McGraw-Hill.

Lonergan, Stephen C. 1981. "A Methodological Framework for Resolving EcologicalEconomic Problems." Papers of the Regional Science Association 3: 117-34.

Nijkamp, Peter, and Aura Reggiani. Forthcoming. "Logit Models and Chaotic Behavior." Environment and Planning.

Nijkamp, Peter, and Frits Soeteman. 1988. "Ecologically Sustainable Economic Development." International Journal of Social Economics 15, no. 3/4: 88-102. . 1989. "Land Use, Economy and Ecology." Futures (December): 621-34.

Norgaard, R. B. 1984. "Co-evolutionary Development Potential." Land Economics 60, no. 2: 160-73.

Odum, E. P. 1971. Fundamentals of Ecology. Philadelphia: Saunders.

Paelinck, Jean, and Peter Nijkamp. 1976. Operational Theory and Method in Regional Economics. Aldershot, U.K.: Gower.

Pezzey, J. 1989. "Economic Analysis of Sustainable Growth and Sustainable Development." Working Paper 15, Environment Depàrtment, World Bank. Washington, D.C. Processed.

Randall, A., and E. N. Castle. 1985. "Land Resources and Land Markets." In A. V. Kneese and J. L. Sweeney, eds., Handbook of Natural Resource and Energy Economics. Amsterdam, Netherlands: North-Holland.

Shefer, Daniel. 1974. "The Optimal Use of Natural Resources." Journal of Environmental Systems 4, no. 4: 269-79.

Siebert, Horst. 1985. "Spatial Aspects of Environmental Economics." In A. V. Kneese and J. L. Sweeney, eds., Handbook of Natural Resource and Energy Economics. Amsterdam, Netherlands: North-Holland.

Siebert, Horst. 1987. Economics of the Environment: Theory and Policy. Berlin, Germany: Springer.

Smith, V. L. 1977. "Control Theory Applied to Natural and Environmental Resources." Journal of Environmental Economics and Management 4: 1-24.

van den Bergh, Jeroen, Leon C. Braat, Alison J. Gilbert, David E. James, Ger Klaassen, and Frits J. Soeteman. 1990. "Sustainable Use of Natural Resources and Economic 
Development in the Peel." spIDER paper, Institute for Environmental Studies, Free University of Amsterdam (Netherlands).

van den Bergh, Jeroen, and Peter Nijkamp. 1990. "Ecologically Sustainable Economic Development in a Regional System: A Case Study in Agricultural Development Planning in the Netherlands." Research Memorandum, Department of Economics, Free University of Amsterdam (Netherlands).

van den Bergh, Jeroen, and Frits Soeteman. 1990. "Sustainable Economic Development of Global and Regional Systems." Research Memorandum, Department of Economics, Free University of Amsterdam (Netherlands).

Vincent, D. P. 1982. "The ORANI Approach to Quantitative Modelling of the Australian Agricultural Sector." European Review of Agricultural Economics 9: 415-42.

Wilkinson, R. S. 1973. Poverty and Progress. London: Methuen.

World Bank. 1987. Environment, Growth and Development. Development Committee Pamphlet 14. Washington, D.C.

WCED (World Commission on Environment and Development). 1987. Our Common Future. New York: Oxford University Press.

Zimmermann, Klaus. 1982. "Institutional Aspects of Integrated Planning Processes." In Y. J. Ahmed and F. G. Muller, eds., Integrated Physical, Socio-Economic and Environmental Planning. Dublin, Ireland: Tycooly International Publishing. 


\title{
Comment on "Regional Sustainable Development and Natural Resource Use," by Nijkamp
}

\author{
Kirit S. Parikh
}

Professor Nijkamp's paper raises some difficult but very important issues concerning sustainable development at the regional level. Somewhere between the Stockholm conference of 1972 and the latest report of the Brundtland Commission (WCED [World Commission on Environment and Development] 1987), a global consensus emerged on the need for sustainable development, and both developed and developing countries now endorse it. At the Stockholm conference the environmental problem was seen largely as a problem of pollution, and Indira Gandhi summarized the viewpoint of developing countries when she asked, "Are not poverty and need the worst polluters?" The implication was that taking care of poverty would solve the problems of pollution in developing countries. Since then, developing countries have noticed that development has not taken care of their environmental problems and that issues of air and water pollution, urban slums, soil degradation, desertification, and deforestation are widely present today. Moreover, these problems have the most severe effects on the poorest segments of society. Thus, developing countries have recognized that not all development is desirable and that only sustainable development is worthwhile.

Although industrial countries have made significant progress in cleaning up their own pollution of air and water, they have been made more keenly conscious of the need for development that would sustain the global commons by the emergence of global environmental problems such as the greenhouse effect and the hole in the ozone layer.

Still, what is meant by sustainability is not yet clear. The definition given by the Brundtland Commission, which I come to shortly, needs to be translated into an operational, measurable, and monitorable concept. Sustainability is essentially a holistic notion, and all aspects of the system need to be included in it. It is therefore difficult to define precisely. Defining sustainability for a sector, a specific resource, a subsystem, or a subregion is even more difficult. Yet, even when one thinks globally, one has to act locally. It is only local populations that are likely to have the necessary knowledge and understanding as well as the ability to take the actions needed to preserve the sustainability of the local

Kirit S. Parikh is the director of the Indira Gandhi Institute of Development Research, Bombay, India. (C) 1991 The International Bank for Reconstruction and Development / THE WORLD BANK. 
resource base. It is therefore essential to define the concept of regional sustainable development and to provide a framework for guiding local action.

Nijkamp's paper presents a definition of regional sustainable development that involves only sustainable resource use (SRU), which he does not define. He then proceeds to provide a framework for developing a sustainable development plan for a region, in the course of which various factors that one might consider as necessary conditions to promote sustainable resource use are to be identified. These factors he calls the critical success factors (CSFs). CSFs may be looked upon as the factors that help monitor whether development is proceeding along a sustainable development path. Nijkamp also outlines what analytical models for sustainable development should look like. The special institutional arrangements and policies needed to implement a sustainable development plan are also discussed, and three case studies are presented to illustrate his ideas on regional sustainable development.

Perhaps because Nijkamp's paper covers such a large scope, he has not provided details at the level one would have liked. My comments on his paper, therefore, may be unfair.

The first problem I see is the difficulty of defining sustainable development at a regional level. Nijkamp defines sustainable development as "development that ensures that the regional population can attain an acceptable level of welfareboth at present and in the future-and that this regional development is compatible with ecological circumstances in the long run while it also tries to accomplish a globally sustainable development." In a sense, this is an extension of the definition given in the Brundtland Commission report, which defines sustainable development as the development that meets the needs of the present without compromising the ability of future generations to meet their needs. It also recognizes that sustainable development is not a fixed state but a process of change in which exploitation of resources does take place and that it is not realistic to suppose that every resource can be kept intact everywhere.

The question is at what level should one think of sustainability and over what period. Should sustainability of forests, say, be defined at the level of the globe, nation, region, forest, hectare, or tree? Obviously, it is impossible to preserve every forest or tree. Spatial and temporal depletion of resources must take place, and one has to recognize that one can also restore some resources, augment them, and improve their quality. If we were to try to preserve every resource base for all regions for all times, we would have to forgo so many opportunities that development would become extremely expensive.

When one recognizes this possibility-of spatial and temporal exploitation of resources-the problem of defining regional sustainable development becomes obvious. Does one assume that the population of the region should remain the same? What level of migration in and out of it should be considered a tolerable limit for sustainable development? What about the imports of commodities and resources from outside the region? Once one permits such imports into a region, it is easy to ensure that the development within the region remains sustainable.

As Nijkamp himself points out, the high productivity of Dutch agriculture 
involves Thailand's exports cassava to Netherlands. Dutch livestock activities may be sustainable as a result, but is Thailand's cassava production sustainable? Seasonal migrants from Athens can appropriate the gains from development of tourism of the Sporades Islands, leaving little gain for the islanders. If one does not care what happens outside the region, one can make its development sustainable. Every region in this sense can have regional sustainable development, but such development need not be globally consistent, and it would not result in a globally sustainable development. This problem of defining the boundary conditions or the conditions of trade with other regions is not addressed in Nijkamp's paper. Yet without such a discussion, it seems to me, the problem of defining regional development remains somewhat incomplete.

Sustainability may be defined as the preservation of the production possibilities of an economy to produce the same useful goods and services, including services obtained from the state of nature. Such a definition could provide some guidance (see Parikh 1989) on the rate at which one can exploit exhaustible resources or the level of degradation of renewable resources that may be permitted. However, this raises another issue. In the production of such goods and services, man-made capital and natural resources (we can call the latter environmental capital) can substitute for each other, at least within some limits.

Figure 1 shows that with the present technical knowledge and skills, different combinations of the two types of capital yield the same level of production and define the isoquant $q_{0}$ of production. Initially one may be at a point, $P_{0}$, corresponding to the initial stock of nature, $N_{0}^{\prime}$, and accumulated capital, $K_{0}$. If, as production takes place and some natural resource capital is used up, one remains on the isoquant $q_{0}$, one still may say that one has sustainable development in the sense that the future is able to produce the same output. Thus, one may be at point $P_{1}$, where man-made capital stock has been augmented to the level of $K_{1}$, which is used to produce the same level of output even though the natural resource is depleted, to the level of $N_{1}$.

Such a description illustrates the possibilities of substituting resources or natural environmental capital by man-made capital to sustain output. But we should recognize that isoquant $q_{0}$ is a function of the state of human knowledge and skills. Thus, as technical progress takes place, the isoquant can shift inside to $q_{1}$, in which case the same level of output as before can be produced with less of $N$ as well as of $K$.

Adequate account of these possibilities of technical progress and accumulation of human skills and knowledge is generally not taken in discussions of sustainable development, perhaps for understandable reasons. To the ecologists and environmentalists the notions of substitutability and technological change may ring too much of economists' sophistry, formulated to justify continued neglect of pressing environmental problems. Nonetheless, in a logical system, one ought to account for these possibilities-particularly the possibility that the introduction of new technology and techniques at the level of a region can significantly alter the nature of sustainable development.

In a sense, Nijkamp recognizes all these limitations when he says that the 
Figure 1. Substitution between Man-Made Capital and Environmental Capital at Different Levels of Skills and Knowledge

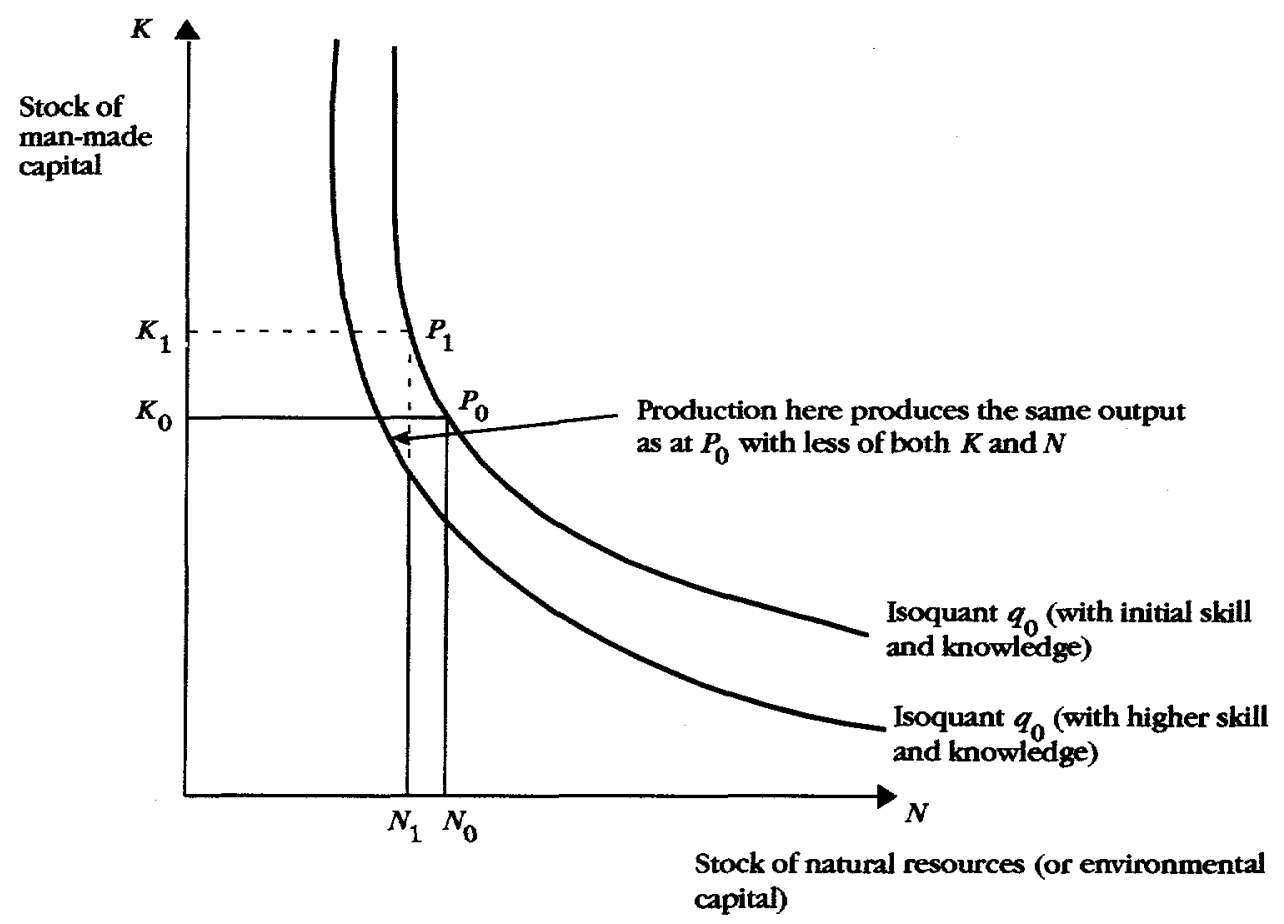

regions are open systems and that sustainable development at the global level may even require sacrificing certain regions. He also recognizes that the carrying capacity of a region is essentially a dynamic concept and that it depends on biophysical behavior as well as on economic activities. Thus, the question that Nijkamp's paper neglects to answer-how does one define in an operational way the boundary conditions for a region-becomes particularly important.

Let me now turn to the operational aspects of the paper. The CsFs, which are defined as the necessary conditions to promote SRUs, are to be identified in a process that involves delineating the characteristics of the region, including its classification based on its socioeconomic circumstances, phase of development, policy of consumption of its natural resources, and generation and depletion rates of its resources. This should be followed with a stocktaking of the characteristics of industrial structure of the region and its interaction with other regions and its relevant global impacts. This is to be followed by a third step of assessment of both probable and possible developments and finally by an identification and evaluation of different development paths. Unfortunately, other than listing these steps in the process, Nijkamp gives no accounting of the 
conceptual difficulty or the analytical processes needed to do this work. In a sense, he provides us with a checklist of things that need to be done but not a full recipe for how to do them. He tells us what are the sights on the way but does not provide the route map.

Perhaps Nijkamp's section. on the models of sustainable development can be looked upon as providing some indication as to how one goes about filling his prescription. As Nijkamp rightly points out, the most significant elements needed in models for sustainable development-which distinguish them from other models used for environmental problems-are two: a module that describes the dynamics of resource bases and ecosystems, and a module that captures the ecological feedback impacts of economic activity on the economic system. These aspects are rightly emphasized, but, unfortunately, Nijkamp does not underline the difficulties of constructing such models. Many of the ecological, biological, physical, and agronomic processes are poorly understood. To incorporate these aspects into models of development will require enormous efforts of communication across different disciplines.

Some years ago, in trying to develop a framework for sustainable agricultural development (see Parikh and Rabar 1981), I was frustrated by the reluctance of soil scientists to extend their knowledge of soil science from the level of a field to that of a region. In exasperation, I posed one of them a question: "If you can generalize from your knowledge based on soil samples that are 3 centimeters in diameter to the level of a field, why are you reluctant to extend this knowledge to a larger region?" I was met by the response, "Perhaps we are being unscientific when we generalize from a sample to the field." How difficult and complex applied studies on sustainable development become can be seen in the case studies reported in J. Parikh (1988). I should mention that Nijkamp does list the different kinds of models, the multiplicity of techniques that one can use, and the role of models in obtaining an understanding in the alternative strategies of sustainability for a region.

Finally, let me turn to the case studies Nijkamp provides to illustrate the use of the ideas and approaches he describes in the first five sections of his paper. The case study of the Peel region in the Netherlands is the only one he describes in enough detail for me to discuss. He notes the different interest groups in that region-the farmers, the drinking-water companies (representing also household interests), the tourist industry, the commercial forest owners (the State Forestry Service and private owners), and the nature conservation lobby (among others the state as the owner of the national park de Groote Peel)-and describes how they compete for the region's resources.

The region's natural resources used as goods are groundwater for drinking and irrigation and timber for paper and pulp. The ecosystems provide services of outdoor recreation and nature conservation while they assimilate surplus ammonium and nitrate from nature.

A business-as-usual scenario serves as a reference for various alternative scenarios Nijkamp develops: no import of $\mathrm{SO}_{2}$ or $\mathrm{NO}_{\mathrm{x}}$ from outside the region, 
continuation of present environmental policy, additional ammonia scrubbing, maximum technical effort, and shifts in land use pattern. For each of these scenarios, the paper describes the impact on concentration of nitrates in deep groundwater, total ammonia release from manure, the soil $\mathrm{pH}$, the volume of shallow groundwater, the stock of different types of trees in the forests, the quality of grass, the volume of deep groundwater, the quality of air, and total value added in the region.

The scenarios illustrate the possibilities of nature conservation and the tradeoff between economic and ecological considerations under alternative policies. They raise a number of questions, however. How realistic or descriptive are the model equations? Is the technical knowledge sound? Are the parameters empirically estimated? What policy instruments are available to realize any one particular desired development path? The fundamental cause of many environmental problems-that of externalities and possibility of free riders-requires that the behavioral responses of the different groups in the region are modeled in an appropriate way to reflect their responses to policy changes. It would be interesting to know how one can design a set of policy instruments that would implement any of the desired solutions at minimal cost to the society.

Land is the most important resource in many developing countries, and any models that deal with problems of land use and changes in the quality of land are of considerable interest to developing countries. Moreover, these problems are further complicated by the importance of distributional considerations in developing countries. Such considerations are perhaps not of particular significance in the Peel area. Yet the Peel area did have a number of interest groups, and it would be interesting to know how the impacts of different policies on their interests were modeled and whether any policy was Pareto-optimal or not.

Nijkamp has addressed difficult and important issues of how to translate the vague notion of sustainable development at the global level to a local actionoriented regional development plan. I only wish he had given us some guidance and details on how to do it rather than the mere tantalizing list of things that need to be done.

\section{REFERENCES}

Parikh, Jyoti K., ed. 1988. Sustainable Development in Agriculture. Amsterdam, Netherlands: Nijhoff.

Parikh, Kirit S. 1989. "An Operational, Measurable Definition of Sustainable Development." Indira Gandhi Institute of Development Research Discussion Paper 21. Bombay: Indira Gandhi Institute.

Parikh, Kirit S., and Ferenc Rabar, eds. 1981. Food for All in a Sustainable World: The iiasa Food and Agriculture Program. Report SR-81-2. Laxenburg, Austria: International Institute for Applied Systems Analysis.

WCED (World Commission on Environment and Development). 1987. Our Common Future. Oxford, U.K.: Oxford University Press. 


\title{
Comment on "Regional Sustainable Development," by Nijkamp
}

\author{
William B. Magrath
}

If I had known how difficult it would be to discuss a paper on sustainable development, I never would have accepted this assignment. Now, having thought about Nijkamp's paper, and Dasgupta and Mäler's, I'm surprised that anyone would be willing to take on the job of writing one. Sustainability is one of those concepts that defies definition, and therefore it ends up with as many definitions as experts (of which there seems to be an infinite supply).

As if sustainability alone weren't bad enough, Nijkamp has chosen to discuss it in the context of regional development and natural resource use. If I'd had to write a paper on sustainable development, I certainly wouldn't have wanted to write this one. Nevertheless, sustainability, regional development, and natural resource use are important topics, they are all interrelated, and I did manage to get myself into this, so I will try to raise some questions and suggest some issues that I think are important for the World Bank and for World Bank economists in particular. I should note from the start that I would go along with many of the recommendations Nijkamp offers, especially the need for natural resource accounting, for taking a holistic approach to problems, and for a multidisciplinary approach.

Starting with my narrowest concern, I'm interested in exactly how Nijkamp quantitatively incorporates natural resources in his three case studies. Given the limitations of space, his description of the three models is understandably quite meager. As someone who also tries-and I admit with a great deal of discomfort-to find real numbers for his models, I would be very interested in how Nijkamp views the generation of model coefficients for processes such as drainage, groundwater recharge, agricultural productivity, erosionproductivity, and so on. I presume that essentially mechanistic relationships, drawn from the technical literature on agronomy, soil physics, and environmental chemistry, are the basis for these models. This "engineering economics" approach is increasingly being used in applied natural resource economics, including World Bank work (see, for example, Dixon, James, and Sherman 1989; Anderson 1987; Bishop and Allen 1989; and Magrath and Arens 1989).

Although I don't know of any practical alternative, I would like to see some

William B. Magrath is a land resource economist in the Agriculture Division of the Asia Technical Department at the World Bank.

(C) 1991 The International Bank for Reconstruction and Development / THE wORLD BANK. 
careful analysis of the validity-both technical and economic-of this approach. Beyond the biophysical dimensions, which are complicated enough, some quite strict conditions must be necessary in the production functions if this engineering economics approach is to be considered reasonable. Working out these necessary conditions would not be especially difficult. We know that elasticities of substitution are not zero, and if we are to have any confidence in the policy implications of models such as these, we need some work in this area.

I would particularly like to know more about the technical efficiency of natural resource use in these models. One of the major lessons that emerges from recent work on environmental issues is the importance of technical inefficiency. That is, on almost any environmental issue-energy output and the greenhouse effect, soil erosion, or deforestation-we know that it is possible to get more out of less using known technology. Energy is perhaps the best example. It takes twice as much energy to produce a unit of gross national product in the United States as it does in Japan, and four times the U.S. rate to produce one unit in China. Failing to account for the possibility of improvement within the framework of existing technology and policies overstates the costs of resolving environmental problems and makes agreement on further policy reform even more difficult than it needs to be.

More interesting, if less concrete, questions are raised by the regional development focus of Nijkamp's paper. To be honest, I'm not sure what defines a region. In Nijkamp's paper a country can be a region, so can a chain of islands, and so can the southeast corner of the Netherlands. These regions are more or less open or closed, in terms of their links to other "regions," and both from a modeling and a policy perspective it is important to ask how closed, if at all, a space must be to qualify as a region.

To provide some perspective on this question of what is a region, let me refer to the work the World Bank is just completing on watershed management in Asia. When we started that work we assumed that we would find that physical linkages from the downhill flow of water would provide an inescapable logic for integrated planning based on watersheds as regions. But over time we found that the technical scope for investment aimed at reducing sedimentation and flooding was severely limited (Magrath and Doolette 1990). Moreover, we have pretty much concluded that various institutional problems make integrated planning in all but the smallest watersheds a practical impossibility.

Thus, even though environmental problems occur across space, geography does not always provide the right unit for addressing them. In the watershed work, because the farm was the unit most susceptible to influence by decentralized incentives, we essentially ended up with the farm as the unit of account, even though it is only partly a physical unit and even though we are concerned with erosion and sedimentation problems that clearly transcend farm boundaries. In truth, the definition of a region, and whether it is a useful unit of account, all depends on the objectives of the analysis.

Also in the context of defining regions, I'm interested in what Nijkamp thinks 
about trade between regions and self-sufficiency. Nijkamp suggests that regional sustainable development "should ensure the regional population an acceptable level of welfare, which can be sustained in the future" and that "it should not be in contrast with sustainable development at a supraregional level." I wonder if this really requires that a region be self-sufficient. What if there is the possibility of trade with a nonsustainably developing region? Other analysts of sustainable development (for example, Daly and Cobb 1990) clearly associate sustainable development with self-sufficiency. They reject trade based on the principle of comparative advantage. Where does Nijkamp stand on this issue? Another way of putting this is to ask if there is some sort of adding-up requirement implied by Nijkamp's notions of regional sustainable development and globally sustainable development. If so, I think it is more than just a political issue, as he suggests; it seems to further undermine the value of regions as a unit of analysis of sustainability.

Another concern about regions: Nijkamp's use of critical success factors (CSFs) conjures up an image of regional development as a linear programming problem. CSFS are essentially constraints; they can have economic or ecological and local or far-removed dimensions. This is fair enough, conceptually quite useful, and not very unusual. My only problem is, who is to be charged with solving the problem? And once the problem is solved, how will the optimal solution be implemented? We all know that real-world physical problems rarely coincide with political boundaries.

In the United States, the experience of the Water Resources Planning Council shows that regional planning of the type Nijkamp seems to envision is difficult to achieve and sustain. For example, one of my old employers, the Great Lakes Basin Commission (GLBC), was charged with providing planning services to the region comprising the nine states bordering the Great Lakes. The GLBC produced an outstanding planning study for the region. However, the GLBC was closed down as one of the first acts of the Reagan administration, with barely a whimper from Congress or the states concerned. The entire planning exercise had no lasting impact on the region.

Even if Nijkamp's planning function can be sustained, how will proposed solutions be implemented? Presumably, he expects that there would be some need for bribery or coercion, or that the optimal solution would emerge from the operation of market forces. It is worth thinking about the fact that the comprehensive resolution of Botswana's land degradation problems in Nijkamp's example will involve changing the behavior of thousands of herders and bushmen. The role of centralized planning in such a situation is clearly limited to diagnosis of problems, but decentralized incentives or direct investments will prove to be essential to their resolution.

Finally, just a few comments on sustainability. Nijkamp uses two, to some extent conflicting, definitions of sustainable development. At one level he seems to embrace the World Commission on Environment and Development (WCED 1987) definition that sustainable development is development that improves the 
standard of living of the current generation without compromising that of future generations. Further on, he describes sustainable development or a "Paretooptimal trajectory in which progress in either the economic or the ecological system would not be to the detriment of the other system" (I tried to draw an Edgeworth Box to describe this, but had to give up). Finally, he seems to settle on sustainable development as something like Norgaard's (1984) notion of coevolution, in which changes in the environment and society induce still further changes in both themselves and in each other.

Where does all this lead us? We've certainly not heard the last of sustainable development. I believe that the future is important and that running out of resources is worth worrying about. But the prospects for reaching an operational consensus on what sustainability requires are, I think, quite slim.

Aside from being intellectually interesting, the sustainability debate does offer the World Bank and economists a few opportunities for productive work. To realize this potential, however, we will need to recast the question. Instead of talking about "sustainable" or "unsustainable," we should be trying to distinguish more from less sustainable.

We seldom have the opportunity to put an economy on a sustainable path. Even if we did, I don't think the kinds of rules that have been put forward to describe steady-state economies would prove very useful. Dasgupta and Mäler discussed the problems with Pearce, Markandya, and Barbier's (1989) "blueprint for a green economy" rule of maintaining natural resource stocks intact. The notion of countervailing projects, "green" projects to make up for dirty ones, an idea that is present in the World Bank's wildland policy, is also quite limited. Big projects only account for a small part of environmental degradation, and no one can seriously think it possible to micromanage all the potentially degrading activities in an economy.

Like it or not, we need to focus on marginal improvements in the environment. Economics is pretty good at working at the margins. We already have some perfectly serviceable analytical tools, and with some minor revisions and extensions, such as expanding national accounts to include natural resources correctly (something that really should not seem unusual), mainstream economics can go a long way toward understanding and alleviating environmental problems.

\section{REFERENCES}

Anderson, Dennis. 1987. The Economics of Afforestation: A Case Study in Africa. Baltimore, Md.: Johns Hopkins University Press.

Bishop, Joshua, and Jennifer Allen. 1989. "The Onsite Costs of Soil Erosion in Mali." World Bank Environment Department Working Paper 21. Washington, D.C. Processed.

Daly, Herman E., and John B. Cobb. 1989. For the Common Good: Redirecting the Economy toward Community, the Environment, and a Sustainable Future. Boston, Mass.: Beacon Press. 
Dixon, John, David James, and Paul Sherman. 1989. The Economics of Dryland Management. London: Earthscan.

Magrath, William B., and Peter Arens. 1989. "The Costs of Soil Erosion on Java: A Natural Resource Accounting Approach." World Bank Environment Department Working Paper 18. Washington, D.C. Processed.

Magrath, William B., and John B. Doolette. 1990. "Watershed Management in Asia: Strategies and Technologies." World Bank Technical Paper 127. Washington, D.C. Processed.

Norgaard, Richard B. 1984. "Co-evolutionary Development Potential." Land Economics 60, no. 2: 160-73.

Pearce, David, Anil Markandya, and Edward Barbier. 1989. Blue Print for a Green Economy. London: Earthscan.

WCED (World Commission on Environment and Development). 1987. Our Common Future. New York: Oxford University Press. 


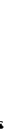




\section{Floor Discussion of the Nijkamp Paper}

A World Bank participant questioned the focus on sustainability in regional growth. An alternative operational focus, he suggested, might be on a strategy of regional resource use that could help the development of other regions. For example, nitrate exploitation in the Atacama Desert of Chile, as a depletion strategy, could have been a rational policy for developing the rest of the country during the nineteenth century. Depletion strategies can be rational, both economically and ecologically, he suggested.

Another World Bank participant asked about the practical role of Peter Nijkamp's model in resolving disputes among the interested parties in the Peel region of the Netherlands. Did the model actually resolve some of the disputes, and did it put in place effective and sustainable policies? In his experience studying and participating in the resolution of resources disputes, the participant argued, fancy mathematical models built by experts were deemed suspect by nearly all of the disputants.

Graham Pyatt (chair) noted that there may be factors other than the current international trade patterns that deserve consideration in explaining high agricultural productivity in the Netherlands. He recalled that Colin Clark's Conditions of Economic Progress had cited William Pettit on the Netherlands' high domestic agricultural productivity from around the end of the seventeenth century.

Pyatt also commented on Nijkamp's Botswana case study and the observation made by William Magrath (discussant) that massive changes in herding behavior in Botswana would be needed to deal with land erosion. Pyatt's understanding of the situation was that it had turned out that the best way to modify herding behavior was to send children to school. Previously, the children had looked after the cattle; after the children began school, it was amazing how quickly electric fences went up. This was an interesting example of the interaction between the environment and household behavior.

Nijkamp began his response to the discussants' comments by noting that he did not think it was meaningful to have a general discussion on terminology about sustainability. The interest and challenge of thinking about sustainability, he argued, came in considering open regional systems-that is, systems with international and interregional trade. It may be better to produce commodities in, or extract raw materials from, places where less harm would be done to the

This session was chaired by Graham Pyatt, professor of economics at Warwick University, U.K.

(C) 1991 The International Bank for Reconstruction and Development / THE WORLD BANK. 
environment than others. So trade is linked to environmental advantage, not just to the standard notions of comparative advantage.

Of course, Nijkamp continued, one could argue that these environmental costs should be internalized through sound economic policies, and the resulting market equilibrium would incorporate externalities. The real problem is that no institution or policy regime exists that can internalize all ecological costs. The question then is a practical one: do regions wait until such a comprehensive system or institutional arrangement comes into being, or do they go ahead and design and implement policies anyway?

Nijkamp gave the example of the debate in the Netherlands about the import of timber from Malaysia and Thailand. The destruction of forests in those countries had motivated parliamentary discussion, and it was thought that the Dutch should use domestic raw material substitutes for tropical wood. However, people soon realized that stopping the import of timber might not solve the problem of deforestation. Timber producers abroad might respond by lowering prices and seeking new markets. Depending on demand elasticities, the timber producers might actually end up depleting more forests as a result of a Dutch policy of substituting domestic raw materials in housing construction. So, international negotiations, the price mechanism, and many other institutions are required in taking account of environmental costs, but even this may not be fully sufficient to internalize them.

Nijkamp mentioned that there are dynamic concerns about the definition of sustainability. If one considers environmental capital per head and uses the Pearce definition of sustainability, discussed by Dasgupta and Mäler in their conference paper, one may then need to consider the expansion of environmental capital to keep pace with population growth. Public preferences regarding the environment are also not stable, and they vary across regions. As an example, Nijkamp cited the fact that environmental concerns were pronounced in the mid-1970s, were relatively muted at the beginning of the $1980 \mathrm{~s}$, and are very high now. Policies have to respond to these popular and political swings.

Nijkamp then turned to the issue of technological change, which he thought was a greatly underestimated factor in sustainability. However, the important question was: which technologies are important from the point of view of sustainability, particularly regional sustainability? It was not enough to speak of the average rate of technological change in aggregate terms. Nijkamp said that the economist's problem lay in trying to measure welfare with a very narrow economic measure-gross national product per capita. This single measure can hardly capture the whole range of welfare effects, including equity and environmental considerations.

It is quite evident, Nijkamp said, that the issues cannot be undertaken by an economist alone: major contributions have to come from environmentalists and resource specialists. Yet the reconciliation of methodologies and the scope of different disciplines is a major task. The problem of coordination becomes 
pressing for ecological phenomena, which never coincide with our administrative boundaries, be they regional, national, or even international.

On the case studies, Nijkamp noted that one of the most difficult tasks is the problem of choosing the policy or control variables. It may sound simple, but in practice, it becomes a very difficult, interactive question. To Magrath's (discussant) question about whether regional sustainability as defined by Nijkamp would also be Pareto-optimal, Nijkamp replied that he agreed with Magrath that the important thing was to distinguish more sustainable from less sustainable. Nijkamp noted in this context that the recent literature makes a distinction between "weak sustainability" and "strong sustainability." Weak sustainability would exist if one made considerable progress on one objective-say, growthwhile progress on other objectives such as environmental preservation suffered, but by not too much, so that the net result for social welfare was still positive. He said that his model was about weak sustainability. Of course, he added, everything depends on how social welfare is defined and estimated, and the estimation of social welfare functions remains relatively poor in economics, so perhaps we have to depend on decision theory and operations research for empirical methodologies. That was why he had introduced multi-objective decisionmaking in his models.

A participant from the International Monetary Fund, referring to the conference paper by Dasgupta and Mäler earlier in the morning and their point about the tie between poverty and environmental degradation, wondered how poverty and the environment interacted, because environmental deterioration and activities such as the search for water and firewood are both outside the national income accounts.

Dasgupta replied that one had to be somewhat catholic in the use of data. There are many activities that are not going to be counted, but in the case suggested, the amount of time spent by women and children in collecting firewood or carrying water provides some signal about the state of the environment and the state of the resource base in that community. So time use or calorie use data are needed to supplement the national or regional income data. Mäler said that national income accounts could include estimates of the value of time and energy used in activities such as collecting fuelwood and fetching water by deriving appropriate accounting prices based on production functions for these activities.

A Bank participant noted that household sample surveys provide much information useful to environmental policy analysis. The challenge is to make effective, systematic use of, for example, time-use surveys and to show that the derived indexes for policy analysis are not sensitive to the large measurement error that comes from using data that originate outside the market. To do that, one's interest must be focused on detecting change rather than levels as such. On this issue, Pyatt observed that the primary problem was that the economists generally did not demand this kind of data from statisticians. 
A participant found the lack of any discussion of population growth in either of the two conference papers puzzling, because one constantly hears strong claims about its impact on global ecology. Put another way, there could be a large negative externality from reproductive decisionmaking, because environmental assets are collectively owned.

Dasgupta agreed that population growth was obviously important. $\mathrm{He}$ and Mäler had not dealt with it simply because there were to be papers on population specifically at the conference. Nijkamp also agreed with the importance of incorporating population growth in ecological models; however, to do so, he warned, will require tremendous amounts of new data-for example, on the use of time and the resources of people more than sixty-five years old for countries with aging populations.

A Bank participant wished to follow up on the point about threshold resource use levels; he felt that besides the measurement reasons Mäler had cited for deriving such levels, there were other very practical and operational reasons for doing so, particularly in irreversible situations. What if a seemingly prohibitive price put on a particular resource to prevent its further use did not, in fact, ultimately prevent its use because someone was willing to pay that price? Often, to deal with such circumstances, a threshold level makes more sense, the participant argued. Mäler agreed that in many circumstances an environmentally conscious development policy based on rules of thumb could be preferable to relying on the price system.

Another Bank participant said that authors of the papers under discussion seemed to have different ideas on the substitutability of capital and natural resources: Mäler seemed to think that it was an empirical question; Dasgupta seemed to say that there was not much substitutability; and Nijkamp suggested that one's beliefs about the degree of substitutability would influence the definition of sustainability. The questioner asked for an elaboration of their positions.

On the question of defining sustainability (either as nondecreasing per capita welfare or a nondecreasing natural resource stock over time) and the issue of substitutability, Mäler argued that the basis should be welfare. If substitutability between natural and man-made capital is nil, he said, then we should preserve natural resources; this is a consequence, however, not the basis for the definition of sustainability. He reiterated that there is no general answer on substitutability of capital; it depends on the specific circumstances.

Dasgupta said that spending a lot of time arguing whether there was or was not substitutability, or what it might mean, is not likely to yield much progress. Dasgupta argued instead for paying attention to why existing social arrangements may not be right in the context of the environment, and what the economist's tools tell us in terms of the policies to be followed in such cases.

Regarding substitutability between natural and man-made capital, Nijkamp said that much depended on the time horizon being considered. A pesticide ban in the short run may lead to reduction in agricultural activity, but it may pro- 
duce favorable long-run environmental conditions that are also a necessity for agricultural production.

In closing, Nijkamp reiterated the central importance of incorporating social externalities, through shadow prices, to the maximum extent possible in production, technology, and factor choices. Too often economists wait until externalities begin to appear, and then it is very difficult to internalize them into the market mechanism.

Pyatt thanked the speakers, discussants, and conference participants for their stimulating contributions. 
